\title{
Technologies Enabling Situational Awareness During Disaster Response: A Systematic Review
}

\author{
Tara Kedia, MD (1); Jeremy Ratcliff, BS; Megan O'Connor, BS; Sophia Oluic, MPH;
} Michelle Rose, MS; Jeff Freeman, PhD, MPH; Kaitlin Rainwater-Lovett, PhD, MPH

\section{ABSTRACT}

Situational awareness (SA) is critical to mobilizing a rapid, efficient, and effective response to disasters. Limited by time and resources, response agencies must make decisions about rapidly evolving situations, which requires the collection, analysis, and sharing of actionable information across a complex landscape. Emerging technologies, if appropriately applied, can enhance SA and enable responders to make quicker, more accurate decisions. The aim of this systematic review is to identify technologies that can improve SA and assist decision-making across the United States Government and the domestic and international agencies they support during disaster response operations. A total of 1459 articles and 36 after-action reports were identified during literature searches. Following the removal of duplicates and application of inclusion/exclusion criteria, 302 articles and after-action reports were included in the review. Our findings suggest $\mathrm{SA}$ is constrained primarily due to unreliable and significantly delayed communications, timeintensive data analysis and visualization, and a lack of interoperable sensor networks and other capabilities providing data to shared platforms. Many of these challenges could be addressed by existing technologies. Bridging the divide between research and development efforts and the operational needs of response agencies should be prioritized.

Key Words: disaster response, emergency responders, multi-agency coordination, situational awareness, technology

$\mathrm{F}$ rom 2004 to 2014, the International Federation of Red Cross and Red Crescent Societies estimated that, on average, more than 12 disasters occurred every week around the globe. ${ }^{1}$ Some of these disasters had catastrophic consequences. In the United States, Hurricanes Katrina, Harvey, and Maria collectively killed at least 4500 people and caused $\$ 376$ billion dollars in damages..$^{2-5}$ Unfortunately, these catastrophic events are becoming more common due to a convergence of anthropomorphic and climatological factors. Climate change is driving an increase in the frequency and severity of natural disasters, whether measured by number of events or economic damage, ${ }^{6-8}$ while the recent rise in intra-state warfare and the interconnectedness of the global supply chain have increased vulnerability to man-made disasters., ${ }^{9,10}$ In addition, a global movement toward urbanization increases the potential impact of disasters as more individuals become exposed to the same hazards. Currently, $55 \%$ of the world's population lives in urban areas, and that number is expected to rise to $68 \%$ by 2050. ${ }^{11}$ Already, $60 \%$ of cities with $500,000+$ citizens are at a marked risk of a natural disaster, ${ }^{12}$ and urban settlements in low- and middle-income countries in Asia, South America, and Africa, the regions with the highest projected rates of urbanization, are located in areas with uniquely high risk to natural disasters. ${ }^{13}$ These heightened risks necessitate novel approaches to decrease morbidity and mortality driven by disasters.

The United States National Response Framework (NRF) defines the disaster lifecycle as comprising prevention, protection, mitigation, response, and recovery. ${ }^{14}$ Prevention, protection, and mitigation all take place before a disaster's occurrence, while recovery occurs after the acute response has subsided. Response begins the moment a disaster affects an area. Disasters are fast moving, highly dynamic events, and the response can involve a wide range of actors, including state and local authorities, federal and international agencies, and the populations affected. Response is limited by time, capital, and human resources, which drive the need to quickly and efficiently mobilize limited supplies and personnel. Effective mobilization, particularly between agencies with disparate priorities and objectives, requires emergency managers to have a complete understanding of the situation in the field. This knowledge framework is frequently referred to as situational awareness (SA). In a disaster response, 
Emergency Operations Centers (EOCs) act as information hubs and are responsible for the attainment and sharing of SA vertically and horizontally across decision-makers and actors in the field.

SA is particularly challenging to obtain during a disaster due to logistical challenges in collecting and disseminating complete and high-quality information from first responders to EOCs, the constantly shifting needs and resources in the field, and organizations using different information sharing platforms. With incomplete SA, the decisions made within EOCs will be inefficient and potentially ineffective, as they target a situation different to the one at hand. The 2004 Indian Ocean Tsunami, which resulted in the death of over 227,000 people, was a somber illustration of the consequences of failing to achieve SA. The response was plagued by poor SA from the moment the tsunami was triggered, including the lack of a tsunami warning system, the inability of the Pacific Tsunami Warning Center to contact government officials in Indonesia, and the absence of a system to alert the public once the tsunami was identified. ${ }^{15,16}$ Domestically, this phenomenon was also demonstrated during the Deepwater Horizon response, when the EOC had incomplete and excessively technical data on the oil flow rate and well capacity, the locations of first responders, and the availability of resources, resulting in the inappropriate use of a well-sealing procedure that failed to halt the oil spill. ${ }^{17}$

Emerging technology, if appropriately applied, has the potential to revolutionize response operations. A prior review published by 2 authors involved in this study (J.R., J.F.) found that the use of information and communication technologies in disaster response is generally limited in geographical application, fails to identify the intended end-users, and does not address the challenges with implementing the technology in the field. ${ }^{18}$ However, this prior study was limited by the lack of review of after-action reports (AARs). For example, the Deepwater Horizon AAR highlighted a lack of interoperability between technologies and information sharing platforms, challenges in interpreting and storing large amounts of gathered data, and time delays in processing data, resulting in unactionable information being delivered to decision-makers. ${ }^{17}$ This indicates that the technologies currently in use are not adequate to obtain SA, and may limit the speed, efficiency, and effectiveness of response efforts, but these specific challenges may not have been appreciated using the previous methodology, motivating this present study.

An inventory of existing SA technologies would allow response agencies to match their needs to available technologies. Likewise, identification of the technological capabilities that are currently unavailable would allow for strategic investment in these technologies. However, no systematic review of SA technologies relevant to disaster response was found in the academic literature. Therefore, the objectives of this review were to: identify technologies for gaining SA that are currently being applied to disaster response or are in development, classify these technologies based on their maturity level for fielding, and determine the SA needs of response agencies relative to the technologies currently available or emerging.

\section{METHODS}

The authors conducted a systematic literature review using the Preferred Reporting Items for Systematic Review and MetaAnalysis (PRISMA) Guidelines to identify technologies currently being used to enable SA during disaster response. ${ }^{19}$ This review included published journal articles, conference proceedings, and AARs describing SA technologies undergoing research, development, testing, and evaluation in real or simulated disaster responses.

Searches for journal articles and conference proceedings were conducted in May 2019 in the following databases: Web of Science, Embase, CINAHL, BIOSIS, PubMed, and Scopus. Searches included the terms listed in Table 1. English language, original research, and conference reports published between the years 2000 and 2019 were included if describing technology for SA in a real or simulated disaster. To facilitate the management of the systematic review, the Covidence platform ${ }^{20}$ was used to import citations and screen titles and abstracts. Covidence uploaded citations and removed duplicate entries among the databases, permitting more efficient screening and review of reports. All initial steps, including title and abstract screenings, were independently conducted by a random selection of 2 individuals (T.K., J.R., M.O., S.O., M.R., K.R.L.), with conflicts resolved by a third individual. All steps from assessment of full texts for inclusion onward were performed by a single individual, and data were extracted using a standardized Microsoft Access database.

Searches for AARs were conducted in Columbia International Affairs Online, ${ }^{21}$ Policy File Index, ${ }^{22}$ Homeland Security Digital Library, ${ }^{23}$ the Defense Technical Information Center, ${ }^{24}$ National Technical Information Service, ${ }^{25}$ Transport Research International Documentation, ${ }^{26}$ Google, ${ }^{27}$ and Global Health Database. ${ }^{28}$ AARs were screened separately from journal articles and conference proceedings using the same inclusion and exclusion criteria (Table 1).

Each full text was reviewed and the following data were extracted from each record: type (Supplemental Tables S1 and S8), purpose (Supplemental Table S2), and maturity of the technology (Supplemental Table S3); organization potentially using the technology (Supplemental Table S4); intended technology end-user (Supplemental Table S5); type of disaster in which technologies were or could be applied (Supplemental Table S6); and gaps in obtaining adequate SA during disaster response (Supplemental Tables S7 and S9). These "gaps" were defined as inadequate or absent technological capabilities, processes, systems, or knowledge during disaster response that were explicitly described in an article or AAR. For each full 


\section{Search Terms and Exclusion Criteria for Abstract Review}

Systematic review search terms

\section{Exclusion Criteria}

Non-English language

Review/OpEd

No or unclear SA capabilities

No or unclear technology

Other (disaster OR cyclone OR hurricane OR tornado OR storm OR high water OR wind driven water OR tidal wave OR tsunami OR earthquake OR volcanic eruption OR landslide OR mudslide OR snowstorm OR drought OR fire OR flood OR explosion OR terrorism OR terrorist attack OR pandemic OR epidemic OR outbreak) AND ("situation* awareness" OR "data integration" OR "integrated information" OR "information integration" OR "knowledge integration" OR "continuous monitoring") AND (technology OR dashboard OR ICT OR communications OR "mobile applications" OR machinery OR equipment OR software)

No English translation of full text exists, or English translation was completely unintelligible.

Article did not report new concepts or primary or original data collection. (Note: this criterion was not used for AARs.) SA was mentioned in abstract but not directly incorporated into the technology. Notification systems for the public were excluded.

No or poorly described technology.

Did not meet the inclusion criteria or objective of the review and did not align with an exclusion criterion.

Abbreviations: AAR, after action report; SA, situational awareness.

text record, data were entered in a "choose all that apply" manner, in which each full text record could describe multiple types of technologies at various levels of maturity that could be used by multiple types of organizations. Details on the data types, categories, and definitions are available in the Supplemental Material.

As no quantitative or qualitative data were collected in this systematic review, quality assessment metrics were not applied to assess the methods of the journal articles. The statistical significance of the data was determined using Pearson's Chi-square test of Independence for contingency tables containing only data from articles, or Fisher's exact test for contingency tables that included data from only AARs or AARs and articles. Results were considered significant if the $P$-value was $<0.05$.

\section{RESULTS}

Before beginning the systematic review, an initial search of the academic literature, governmental, and intergovernmental agency documents showed that there are no consensus definitions for the key terms being used in this review, namely SA, technology, and disaster. In particular, for the term "disaster," there are a wide range of definitions in the literature and used by federal and intergovernmental agencies (Supplemental Tables S10 and S11). The Federal Emergency Management Agency's (FEMA's) response is governed by the Stafford Act, which contains the legal definition of a "major disaster" and determines FEMA's ability to provide federal funding and respond to a domestic disaster. ${ }^{29}$ A notable exclusion from the Stafford Act definition is a health-related disaster, such as an infectious disease epidemic. Another definition of interest was from the United Nations Office for Disaster Risk Reduction, which defines a disaster as "a serious disruption of the functioning of a community or society involving widespread human, material, economic or environmental losses and impacts, which exceeds the ability of the affected community or society to cope with using its own resources". ${ }^{30}$ Unlike the Stafford
Act, this definition includes health-related disasters; however, it also includes exclusively economic disasters such as the 2008 financial crisis, which would not be considered a disaster by most response agencies. Ultimately, no perfect definition existed that precisely mapped to the scope of this project, so an established definition was adapted. Not all agencies' response activities are intractably linked to their definition of a disaster; however, it is important to define the scope of focus for this review.

For the purposes of this review, the term disaster was derived from the definition in the Stafford Act, ${ }^{29}$ in which "determination of the President" was removed to accommodate disasters taking place outside of the United States, while "epidemic or outbreak" was added to accommodate health-related disasters (shown in italics in Table 2). The definition of SA was taken directly from the First Edition of the NRF. ${ }^{31}$ Technology was defined ad hoc, as definitions identified in standard dictionaries (eg, "the practical application of knowledge especially in a particular area" ${ }^{32}$ ) were nonspecific. The exact definitions used in the present review served as inclusion criteria (Table 2).

A total of 1459 articles and 36 AARs were identified during literature searches. Following removal of 284 duplicate records, exclusion of 667 records during abstract screening, and exclusion of 242 records during full-text review, 302 records ${ }^{17,33-333}$ were included for data extraction (Figure 1). The most common reason for exclusion of a record during full-text review was due to it being a review study or opinion/editorial.

The included articles and AARs skewed to recent years (Supplemental Figure S1), with $79 \%$ of the articles and $90 \%$ of the AARs being published in the last decade. The majority of technologies described in articles were related to responses to natural disasters (238 of 282 included articles, $84 \%$ ) (Figure 2). The natural disasters to which the greatest proportions of technologies were applicable were hydrological 


\section{TABLE 2}

\section{Definition of Terms}

\section{Term}

Situational awareness (SA)

Technology

Disaster

\section{Definition}

The ability to identify, process, and comprehend the critical information about an incident. ${ }^{31}$

Machinery, equipment, or software developed from the application of scientific knowledge.

"Major disaster" means any natural catastrophe (including any hurricane, tornado, storm, high water, wind-driven water, tidal wave, tsunami, earthquake, volcanic eruption, landslide, mudslide, snowstorm, drought, epidemic, or outbreak), or, regardless of cause, any fire, flood, or explosion, in any part of the United States, which causes damage of sufficient severity and magnitude to warrant major disaster assistance to supplement the efforts and available resources of States, local governments, and disaster relief organizations in alleviating the damage, loss, hardship, or suffering caused thereby. ${ }^{29}$

Note: The superscripts are references included in the bibliography of the manuscript.

\section{FIGURE}

\section{Inclusion and Exclusion of Reports During Screening and Full-Text Review.}

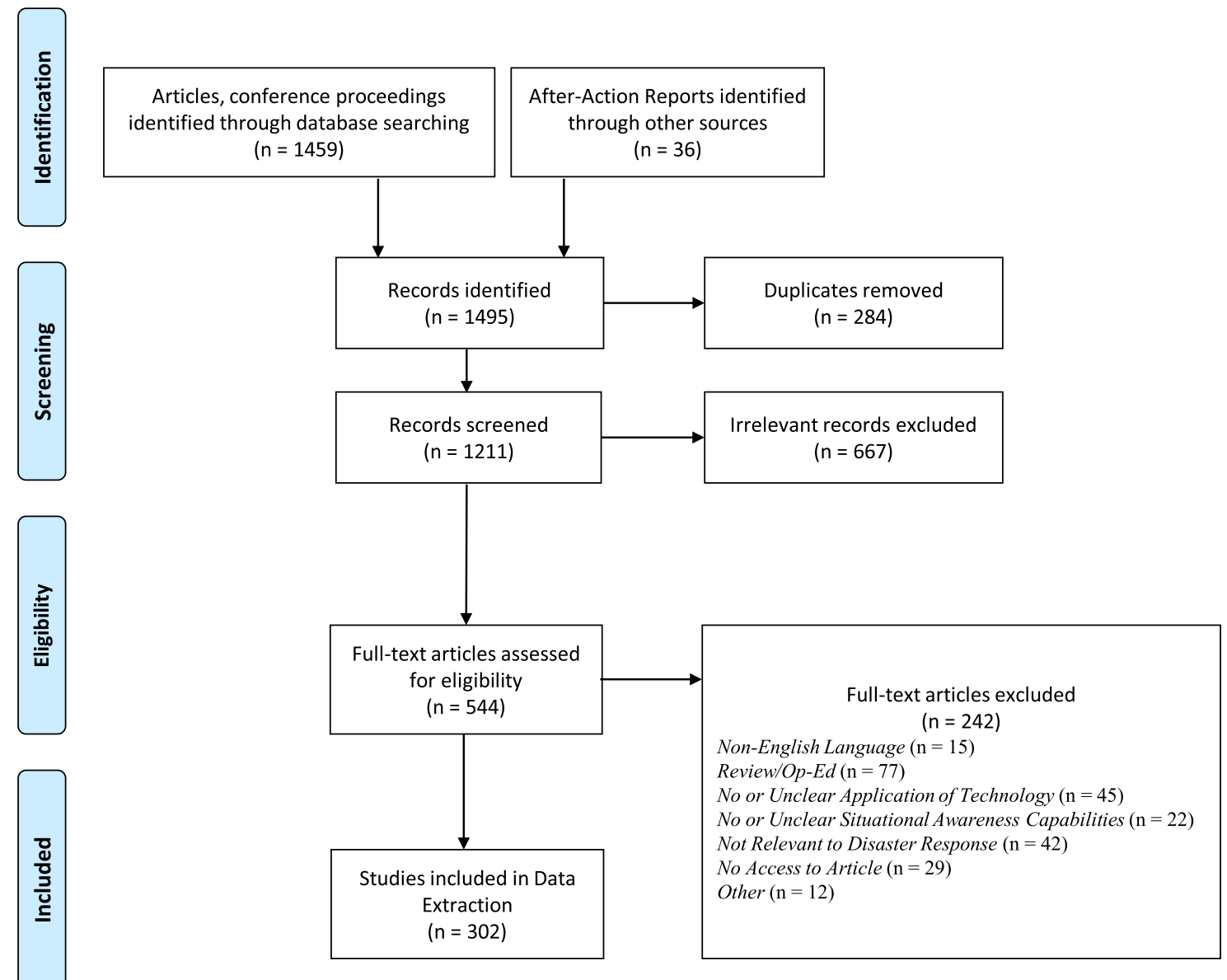

(153 articles) and geological disasters (142 articles). In addition, a large number of technologies from the articles could be applied to accidental or deliberate disasters (163 articles). These categories were not exclusive, and technologies were sorted into 1 or more categories, depending on the use case described by the article's authors, or use cases envisioned by the systematic review team.

Technologies were categorized based on the technology type and purpose. Technology types varied, with the most common 
Disaster Type to Which Technology Was Applied (Number of Articles Only, $n=282$ Articles).

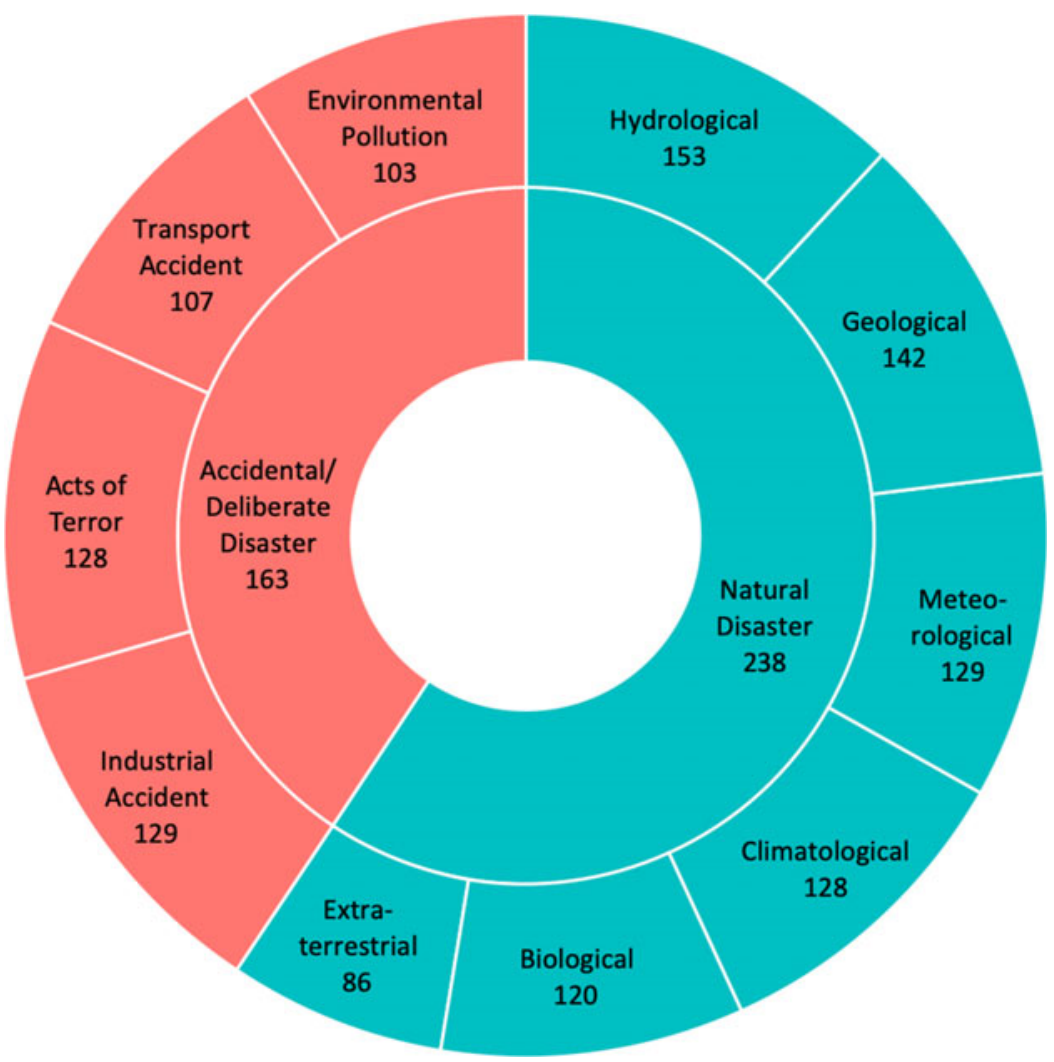

types in articles being data analysis (52\%) and sensor technologies $(42 \%)$, while the most common types in AARs were communications $(90 \%)$ and user interface technologies (55\%) (Figure 3). Communications and user interface technologies were significantly more likely to be mentioned in AARs, while data analysis technologies were significantly more likely to be mentioned in articles. In addition, technologies that performed data aggregation and data generation or collection were significantly more likely to be mentioned in AARs, and technologies that performed data interpretation were significantly more likely to be mentioned in articles (Supplemental Figure S2).

Most technologies were not associated with certain disaster types, with the exception of robotics technology. Robotics technology was significantly more likely to be mentioned in relation to accidental or deliberate disasters in articles (Figure 4), such as unmanned vehicles that could remotely sense radiation in a nuclear disaster ${ }^{216}$ or identify an oil spill in the ocean. ${ }^{120}$ There was no clear trend in the technology types mentioned over time.

Technologies were also categorized by their maturity, their intended end-user within a disaster response agency, and by the organizations likely to use the technology, none of which were mutually exclusive. End users and organizations included those explicitly reported in the article, as well as those who could potentially leverage the technology. The majority of technologies were intended for use by EOC staff $(84 \%$ in articles and $90 \%$ in AARs). In addition, technologies intended for use by first responders were significantly more likely to be mentioned in AARs (Supplemental Figure S3). The most common organization in which technologies could be applied was the Department of Homeland Security (DHS) (72\%) (Figure S4). The majority of technologies in articles were still immature, being at the pilot/proof of concept stage or earlier (79\%) (Supplemental Figure S5). The early technology maturity level was similar across all technology categories (Figure 5).

Gaps explicitly mentioned by the authors that might limit the use of a technology were mapped to 10 categories. These gap categories were composed of numerous individual gaps (Supplemental Table S9). The 3 most common gap categories were inadequacies in communications and connectivity $(95 \%$ of AARs, $21 \%$ of articles), analysis and visualization (35\% of AARs, $17 \%$ of articles), and interoperability and sensor capabilities (35\% of AARs, $16 \%$ of articles) (Figure 3). Gaps in 
FIGURE 3

Technology and Gap Categories Mapped by Record Type ( $n=282$ Articles, 20 AARs).

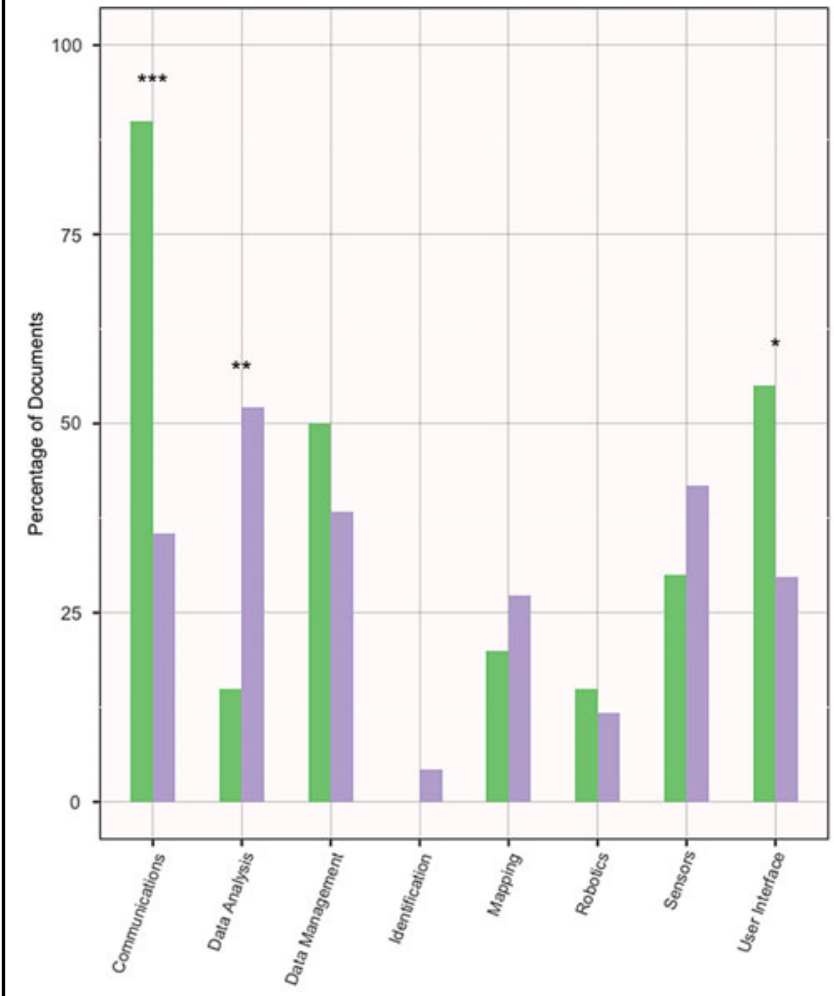

Technology Category Identified

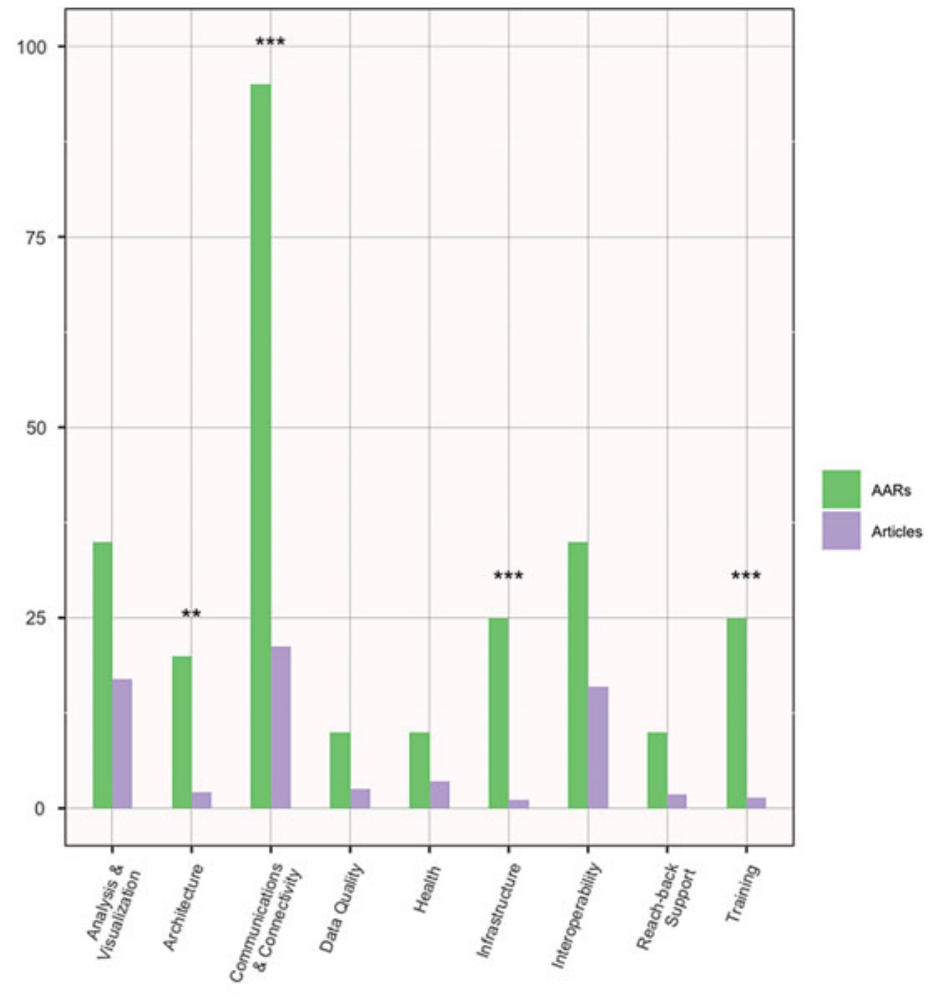

Gap Category Identified architecture, communications and connectivity, infrastructure, and training were significantly more likely to be mentioned in AARs.

There was no clear trend in the gap categories over time. Most gaps were not clearly associated with certain types of disasters, with the exception of health gaps, which were significantly more likely to be mentioned in relation to natural disasters in articles (Figure 4).

\section{DISCUSSION}

This systematic review defined disasters similarly to the Stafford Act, with the addition of health-related disasters. For the purposes of AARs and potential applicability of these findings, disasters located anywhere in the world were included. The included records skewed to more recent years, likely due to the increasing volume of publications over time, consistent with the trends seen in the initial 1495 reports identified in the literature searches.

The finding that the majority of technologies were intended to be used by EOCs is likely reflective of the scoping of this systematic review, which focused on technologies providing SA to disaster responders, and excluded technologies aimed for use by the general public. In addition, AARs were significantly more likely to mention technologies for first responders, which may be because AARs provide detailed analyses of all participants in a response, whereas articles do not always describe all potential end-users or use cases of their technologies. It is also possible that this discrepancy exists because of inadequate research on technologies for first responders, such as safe and timely recall and evacuation of first responders, ${ }^{217,254}$ tracking the locations and status of fellow first responders and required supplies, ${ }^{17,39,217,248,249}$ and reliable communication of data to and from the EOC. ${ }^{17,35,247,254,255}$ The most frequently mentioned sector in which technologies could be implemented was DHS, the parent organization to FEMA and the US Coast Guard, which are among the federal agencies most frequently involved in disaster response activities in the United States. SA technologies identified in this review were relevant to all types of disasters, with all types of disasters being well-represented.

Similar types of gaps were described over time, suggesting chronic issues in disaster response technologies. However, there was inadequate data to determine whether these gaps were resolved over time. The most prevalent gap in articles 
FIGURE 4
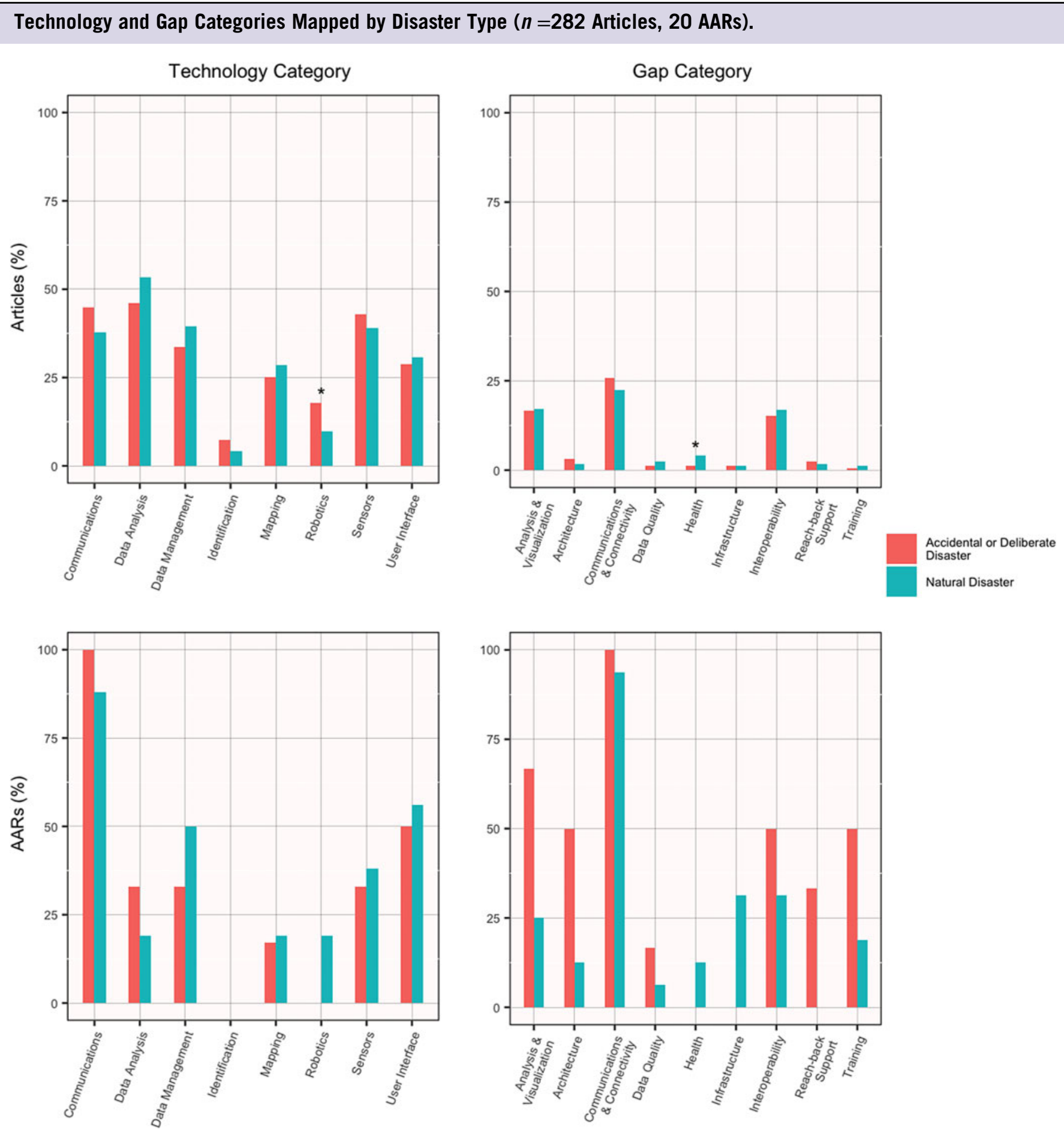

and AARs was communications and connectivity, followed by analysis and visualization, and interoperability and sensor capabilities. Communications, data generation/collection, user interface, and data aggregation technologies were significantly more frequently mentioned in AARs, suggesting that the research community may not be prioritizing the areas of greatest need by the operations community. While the majority of AARs described using the first 3 technologies, the technologies were inadequate; thus, the gap persists.

Meanwhile, research on data aggregation technologies was limited, which may reflect a perception among researchers that 


\section{FIGURE 5}

\section{Technology Categories Versus Technology Maturity Levels (Articles Only, $\boldsymbol{n}=\mathbf{2 8 2}$ Articles).}

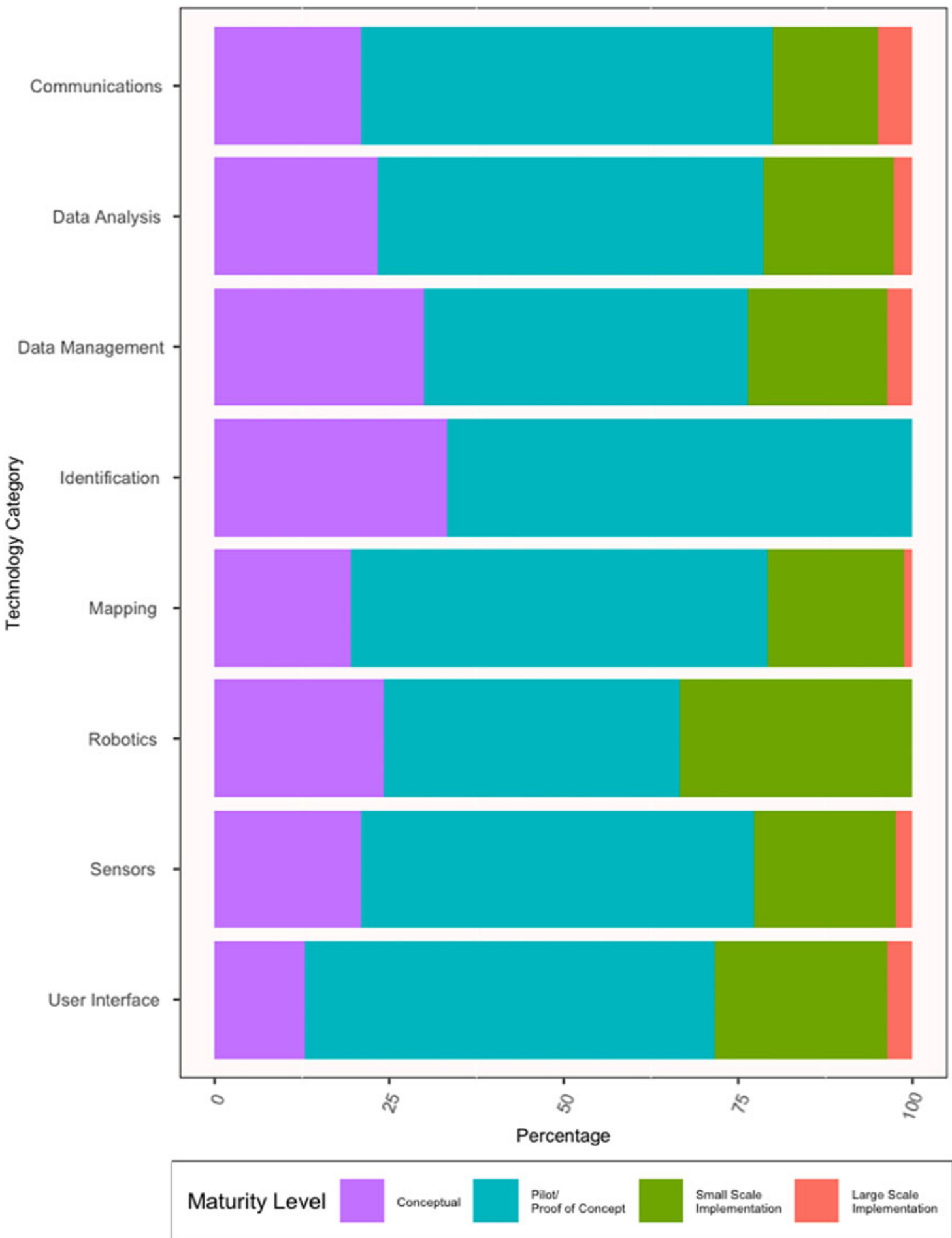

high-quality data aggregation technologies already exist. Data analysis, interpretation, and identification technologies were mentioned by very few or no AARs, likely because AARs were inadequately detailed. In addition, gaps in communications and connectivity, infrastructure, training, and architecture were mentioned more often in AARs than in articles. Given the scope of the systematic review, which focused on technologies, it is possible that not all articles mentioning gaps 
in infrastructure, training, and architecture would be located by the search terms used. However, the search terms did identify articles focusing on communications and connectivity gaps. In other words, disaster response agencies were frequently reporting gaps in communications and connectivity, but academics and researchers were not, suggesting a disconnect between the state of the science and the technologies being used by disaster response agencies.

Communications and connectivity challenges, such as damaged or absent infrastructure, ${ }^{35,162,247,255}$ inadequate bandwidth for data to be transmitted from first responders in the field to the EOC,,$^{35,255}$ and high call and email volumes, ${ }^{245,247,254}$ are extremely common during disasters. Articles in this review highlighted promising potential solutions to these challenges, such as delay-tolerant networks, ${ }^{144,330,331}$ mobile ad-hoc networks ${ }^{178,273,284,287-289}$ including those using drones, ${ }^{10,144}$ ultra-wideband technology, ${ }^{63,152}$ and more. However, they are largely still immature. Additional development of these technologies to reach a higher maturity level and additional investment into communications infrastructure, such as redundant systems, are needed to improve SA during disaster response.

Data analysis was identified as another significant challenge during disaster response. For example, responses to 2 of the most salient recent disasters, the Deepwater Horizon incident and the Fukushima nuclear disaster, experienced difficulty with processing, modeling, and understanding highly technical data ${ }^{17,243}$; inadvertent omission of certain sensor data in models that might have predicted the Tōhoku tsunami ${ }^{252}$; and an overwhelming volume of data to be processed. These issues required substantial investments of time, energy, and resources. ${ }^{17,243}$ The AAR focusing on the 2017 wildfires in Sonoma, California, specifically noted that the Geographic Information Systems technology being used during the response was outdated. ${ }^{247}$ These findings suggest limited penetrance of novel data analysis technologies among disaster response agencies, and present an opportunity for disaster response agencies to increase the efficiency and effectiveness of their handling and interpretation of data through adoption of these technologies.

For example, while a minority (15\%) of AARs reported using data analysis technologies during disaster response, newer types of these technologies now exist, such as those using artificial intelligence and machine learning (AI/ML), which have the potential to autonomously ingest, analyze, generate anomaly alerts, and make inferences and conclusions about large volumes of data in real time. Examples included ML analysis of social media posts to detect and localize an incident ${ }^{59,145,172}$ and machine vision-based detection of anomalies, such as fire, and prediction about the severity of disaster damage. ${ }^{175,177}$ If implemented, $\mathrm{AI} / \mathrm{ML}$ has the potential to revolutionize SA during disaster response operations. Articles also mentioned data analysis architectures, such as fog and edge computing, ${ }^{55,65}$ that enable data processing and analysis (including sensor data and video footage) close to the field collection site, rather than requiring transmission to a central server in the EOC for integration and analysis and transmission back to first responders, thus saving valuable time during a disaster response.

While sensor capabilities were identified as another gap during response activities, many articles described technologies to overcome these limitations. Examples included remote sensors, such as satellites and drones, to detect conditions on the ground in difficult-to-access regions ${ }^{41,82,87,138,158,216,261,274,276,316}$; infrared sensors that enable image detection in low-visibility conditions, such as nighttime, smoke, or bad weather ${ }^{43,220,231,277}$; and Radio Frequency Identification (RFID), which is a low-power device that can track the location of disaster supplies and victims, ${ }^{49,90,285}$ as a replacement for spray-painted Building Marking Systems ${ }^{287,288}$; and more. Other articles described architectures for integrating sensor data from different networks in real time,${ }^{64,301}$ thus providing timely and common SA to all response agencies.

Finally, AARs identified data aggregation technologies, such as WebEOC and other shared platforms, as a major area for improvement. These shared platforms were not portable into the field, meaning that first responders used paper to collect data, ${ }^{243}$ and they often required a high degree of customization before use. ${ }^{243,245}$ Other challenges with shared platforms were related to gaps in communications and connectivity, training, and interoperability. For example, AARs reported numerous users whose accounts had not been authorized to access a shared platform, ${ }^{245,253}$ inadequate training of staff to effectively use the shared platform, resulting in paper-based data aggregation in EOCs, ${ }^{243}$ poor interoperability between computing infrastructure, ${ }^{17}$ and variable data security requirements at different agencies, ${ }^{17}$ resulting in ineffective data sharing.

In some cases, a shared platform was not available during the response. ${ }^{162}$ It may be valuable to conduct additional research and development to make such data aggregation platforms more user-friendly to limit the amount of training required for their effective use, and to enable their use in the field. For disaster response agencies and all levels of government, it would be important to establish data use agreements proactively, and to either ensure interoperability between their platforms or switch to a common platform, well in advance of the onset of a disaster. Other key enablers of effective shared platforms include addressing gaps in communications and connectivity, training of staff, and interoperability between sensors and data aggregation platforms.

These handful of examples suggest that there are numerous technologies that can fill gaps in disaster response operations. Introducing newer versions of all types of technologies into disaster response activities has the potential to substantially improve the ability of disaster response agencies to acquire 
real-time information, efficiently analyze the large volumes of data they receive, share information with one another on a common platform, and quickly request and deploy relevant resources during a disaster. In other words, more rapidly transitioning new technologies from researchers to disaster response agencies has the potential to transform disaster response agencies' ability to gain SA, and thus to respond efficiently and effectively during a disaster.

While some technologies mentioned in articles were at the implementation stage, the majority of technologies across all technology categories were immature, which suggests an ongoing challenge in transitioning technologies from research and development to the field. Additionally, this highlights a gap in the systematic evaluation of technologies that have been implemented at large scales. Assessments of mature technologies would aid agencies that seek technologies to expand their capabilities. An important limitation of this systematic review is that the majority of data sources were published research articles or conference proceedings, which are skewed toward reporting immature technologies. Technologies that are beyond early research and development phases, but have yet to be commercialized, were likely excluded by virtue of not having been published. It is also possible that there was variability in the extraction of data. Because the search terms were intended to capture technologies, this systematic review was unable to capture gaps related to policy, training, and other non-technology issues. An important area of further research may include assessing whether a technology gap actually exists among disaster response agencies, or if gaps in policy or training prevent responders from knowing about or properly using available technology. As only English-language articles and AARs were captured in this review, it is likely that both the breadth and maturity of technologies that exist in reality is greater than is indicated by this systematic review. Importantly, the newest, most cutting-edge research will not be captured by a systematic review, particularly in technology fields, due to time lags in writing and publishing of journal articles.

\section{CONCLUSIONS}

Timely, accurate, and complete SA is a key enabler of successful disaster response, where the situation is changing rapidly, resources are limited, and different agencies must coordinate their activities. While policy and governance are the foundation of effective disaster response, technologies have the potential to provide rapid and shared SA for response agencies. This systematic review aimed to identify existing technologies that can be used to obtain SA during a disaster response, classify them based upon maturity level, and compare existing technologies with identified technological gaps in disaster response activities. This review identified a substantial divide between what research shows is the state of the science and the technologies that disaster response agencies are currently using. In addition, while the number of AARs was small, many technological gaps experienced by disaster response agencies seemed to be chronic issues. Further research should investigate whether these gaps are persisting over time.

Moreover, many of these challenges could be partially or fully addressed by implementing existing technologies, particularly in the areas of communications, data analysis, interoperability, and user interfaces. For example, communications and connectivity was by far the most commonly-reported gap in AARs, and was significantly less frequently reported as a gap in articles. Investing in research and maturation of, and implementing existing mature communications technologies, would profoundly impact the ability of EOCs and first responders to share information reliably and rapidly in settings with damaged or absent infrastructure. There is also a need for more research evaluating the large-scale implementation of technologies, which could aid in the uptake of mature technologies by agencies. More efficient acquisition and implementation of relevant novel technologies by disaster response agencies are recommended to improve the speed, quality, and coordination of SA in disaster response.

\section{About the Authors}

Johns Hopkins University Applied Physics Laboratory, Laurel, Maryland (Dr Kedia, Ms O'Connor, Ms Oluic, Ms Rose, Dr Freeman, Dr Rainwater-Lovett) and Nuffield Department of Medicine, Peter Medawar Building for Pathogen Research, University of Oxford, Oxford, United Kingdom (Mr Ratcliff).

Correspondence and reprint requests to Kaitlin Rainwater-Lovett, Johns Hopkins University Applied Physics Laboratory, 11100 Johns Hopkins Road, Laurel, MD (e-mail: kaitlin.lovett@jhuapl.edu).

\section{Acknowledgments}

The team acknowledges helpful discussion with several individuals, particularly including Christine Fox, Matt Schaffer, and Jen Dailey.

\section{Funding}

This study was internally funded by the Johns Hopkins University Applied Physics Laboratory.

\section{Supplementary material}

To view supplementary material for this article, please visit https://doi.org/10.1017/dmp.2020.196

\section{REFERENCES}

1. Hamza M. World disasters report: focus on local actors, the key to humanitarian effectiveness. International Federation of Red Cross and Red Crescent Societies. https://ifrc-media.org/interactive/wp-content/ uploads/2015/09/1293600-World-Disasters-Report-2015_en.pdf. Published 2015. Accessed January 18, 2020.

2. Brown DP, Beven JL, Franklin JL, et al. Atlantic hurricane season of 2008. Mon Weather Rev. 2010;138(5):1975-2001. doi: 10.1175/ 2009MWR3174.1

3. Jonkman SN, Godfroy M, Sebastian A, et al. Brief communication: loss of life due to Hurricane Harvey. Nat Hazards Earth Syst Sci. 2018;18(4): 1073-1078. doi: 10.5194/nhess-18-1073-2018 
4. Santos-Burgoa C, Goldman A, Andrade E, et al. Ascertainment of the estimated excess mortality from Hurricane Maria in Puerto Rico. George Washington University. https://hsrc.himmelfarb.gwu.edu/sphhs_ global_facpubs/288. Published 2018. Accessed January 16, 2020.

5. NOAA Office for Coastal Management. Fast facts: hurricane costs. https://www.coast.noaa.gov/states/fast-facts/hurricane-costs.html. Published 2019. Accessed January 12, 2020.

6. Otto FEL, Philip S, Kew S, et al. Attributing high-impact extreme events across timescales: a case study of four different types of events. Clim Change. 2018;149(3-4):399-412. doi: 10.1007/s10584-018-2258-3

7. Intergovernmental Panel on Climate Change. Managing the risks of extreme events and disasters to advance climate change adaptation: special report of the Intergovernmental Panel on Climate Change. Cambridge University Press. https://www.ipcc.ch/report/managingthe-risks-of-extreme-events-and-disasters-to-advance-climate-changeadaptation/. Published 2012. Accessed January 16, 2020.

8. Coronese M, Lamperti F, Keller K, et al. Evidence for sharp increase in the economic damages of extreme natural disasters. Proc Natl Acad Sci U S A. 2019;116(43):21450-21455. doi: 10.1073/pnas.1907826116

9. Szayna TS, Watts S, O'Mahony A, et al. What are the trends in armed conflicts, and what do they mean for U.S. defense policy? 2017. https:// www.rand.org/pubs/research_reports/RR1904.html. doi: 10.7249/rr1904

10. Umar M, Wilson M, Heyl J. Food network resilience against natural disasters: a conceptual framework. SAGE Open. 2017;7(3). doi: 10.1177/ 2158244017717570

11. United Nations: Department of Economic and Social Affairs. World Urbanization Prospects: The 2018 Revision. Herndon, VA: United Nations Publications. 2019. doi: 10.18356/b9e995fe-en

12. United Nations. The World's Cities in 2018 (ST/ESA/SER.A/417) www.un.org/en/development/desa/population/publications/pdf/ urbanization/the_worlds_cities_in_2018_data_booklet.pdf. Published 2018. Accessed January 16, 2020.

13. Balk D, Montgomery M, McGranahan G, et al. Mapping urban settlements and the risks of climate change in Africa, Asia and South America. Population Dynamics and Climate Change. 2009;(January):80-103. http://www.unfpa.org/public/home/publications/pid/4500. Accessed January $16,2020$.

14. US Department of Homeland Security: Federal Emergency Management Agency. National Response Framework: Fourth Edition. https:/www.fema. gov/media-library/assets/documents/117791. Published 2019. Accessed January 18, 2020.

15. Telford J, Cosgrave J. Joint evaluation of the international response to the Indian Ocean tsunami: synthesis report. Tsunami Evaluation Coalition (TEC). https://www.sida.se/contentassets/f3eOfbc0f97c461c92a60f850a35dadb/ joint-evaluation-of-the-international-response-to-the-indian-ocean-tsunami 3141.pdf. Published 2006. Accessed March 4, 2020.

16. Ozer P, de Longueville F. The tsunami in South-East Asia - a retrospective analysis of the management of an apocalyptic natural disaster. Cybergeo Eur J Geogr Environ Nature, Landsc. 2011;560. doi: 10.4000/ cybergeo. 24607

17. US Coast Guard Incident Specific Preparedness Review (ISPR) Team. Final Action Memorandum - Incident Specific Prepardness Review (ISPR) Deepwater Horizon Oil Spill. 2011. doi: 10.1017/CBO9781107415324.004

18. Freeman JD, Blacker B, Hatt G, et al. Use of big data and information and communications technology in disasters: an integrative review. Disaster Med Public Health Prep. 2019;13(2):353-367. doi: 10.1017/dmp.2018.73

19. Moher D, Liberati A, Tetzlaff J, et al. Preferred reporting items for systematic reviews and meta-analyses: the PRISMA statement. PLoS Med. 2009;6(7):e1000097. doi: 10.1371/journal.pmed.1000097

20. Covidence. https://www.covidence.org/. Accessed January 24, 2020.

21. Columbia University Press. Columbia International Affairs Online (CIAO). https://cup.columbia.edu/reference/ciao. Accessed May 29, 2019.

22. ProQuest. Policy File Index. https://search.proquest.com/policyfile/. Accessed May 29, 2019.

23. Center for Homeland Defense and Security. Homeland Security Digital Library. https://www.hsdl.org/c/. Accessed May 29, 2019.
24. US Department of Defense. Defense Technical Information Center. https://discover.dtic.mil/technical-reports/. Accessed May 29, 2019.

25. US Department of Commerce. National Technical Information Service Bibliographic Database. https://classic.ntis.gov/products/ntis-database/. Accessed May 29, 2019.

26. The National Academies of Sciences Engineering and Medicine. Transport Research International Documentation. https://trid.trb.org/. Accessed May 29, 2019.

27. Google. www.google.com. Accessed May 29, 2019.

28. EBSCO, CABI. Global Health Database. https://www.ebsco.com/ products/research-databases/global-health. Accessed May 29, 2019.

29. FEMA. Robert T. Stafford Disaster Relief and Emergency Assistance Act: Title I: Sec. 102: Definitions: 42 U.S.C. \$ 5122. https://www.fema.gov/ media-library-data/1519395888776-af5f95a1a9237302af7e3fd5b0d07d71/ StaffordAct.pdf. Published 2019. Accessed January 16, 2020.

30. UNISDR. 2009 UNISDR Terminology on disaster risk reduction. https:// www.preventionweb.net/files/7817_UNISDRTerminologyEnglish.pdf. Published 2009. Accessed January 18, 2020.

31. US Department of Homeland Security: Federal Emergency Management Agency. National Response Framework: First Edition. https://www.fema. gov/pdf/emergency/nrf/nrf-core.pdf. Published 2008. Accessed February 5, 2020.

32. Merriam-Webster Dictionary. "technology, noun." https://www.merriamwebster.com/dictionary/technology. Published 2019. Accessed January 16, 2020.

33. Abdullah S. Data integration and chemical modeling. Proc 201411 th Int Bhurban Conf Appl Sci Technol IBCAST 2014 . 2014:85-88. doi: 10.1109/ IBCAST.2014.6778127

34. Ancona M, Corradi N, Dellacasa A, et al. On the design of an intelligent sensor network for flash flood monitoring, diagnosis and management in urban areas position paper. Procedia Comput Sci. 2014;32:941-946. doi: 10.1016/j.procs.2014.05.515

35. Federal Emergency Management Agency. 2017 hurricane season FEMA after-action report. https://www.fema.gov/media-library-data/ 1533643262195-6d1398339449ca85942538a1249d2ae9/2017FEMA HurricaneAARv20180730.pdf. Published 2018. Accessed July 23, 2019.

36. Filho PJ, Simoes P, Raimundo PO, et al. On the design of a contextual emergency state builder with multiple data sources. 2017 IEEE 1st Summer Sch Smart Cities. 2018:85-90. doi: 10.1109/S3C.2017.8501403

37. Fischer JE, Reeves S, Rodden T, et al. Building a birds eye view: collaborative work in disaster response. Conf Hum Factors Comput Syst - Proc. 2015;2015-April:4103-4112. doi: 10.1145/2702123.2702313

38. Flammini F, Mazzocca N, Pappalardo A, et al. Augmenting surveillance system capabilities by exploiting event correlation and distributed attack detection. ARES 2011, Lect Notes Comput Sci. 2011;6908:191-204. doi: 10.1007/978-3-642-23300-5

39. Florida Department of Health. After action report/improvement plan 2010 Deepwater Horizon oil spill. 2010. http://www.floridahealth.gov/ programs-and-services/emergency-preparedness-and-response/trainingexercise/_documents/deepwater-aar.pdf. Published April 30, 2011. Accessed July 23, 2019.

40. Foresti GL, Farinosi M, Vernier M. Situational awareness in smart environments: socio-mobile and sensor data fusion for emergency response to disasters. J Ambient Intell Humaniz Comput. 2015;6(2):239-257. doi: 10. 1007/s12652-014-0227-x

41. Foroushani MA, Damadi S. Remote sensing for physical protection of the pipeline network online monitoring of corridor based infrastructure. In: International Archives of the Photogrammetry, Remote Sensing and Spatial Information Sciences - ISPRS Archives. Vol 38. 2010:16-22.

42. Fox P, McGuinness D, Raskin R, et al. A volcano erupts: semantically mediated integration of heterogeneous volcanic and atmospheric data. Int Conf Inf Knowl Manag Proc. 2007:1-6. doi: 10.1145/1317353.1317355

43. Francisco G, Roberts S, Hanna K, et al. Critical infrastructure security confidence through automated thermal imaging. Infrared Technol Appl XXXII. 2006;6206(May 2006):620630. doi: 10.1117/12.664988 
44. Francisco GL. Amorphous silicon bolometer for fire/rescue. Proc SPIE. 2001;4360:138-148. doi: 10.1117/12.420985

45. Andrews S, Gibson H, Domdouzis K, et al. Creating corroborated crisis reports from social media data through formal concept analysis. J Intell Inf Syst. 2016;47(2):287-312. doi: 10.1007/s10844-016-0404-9

46. Fryer GK, Dennison PE, Cova TJ. Wildland firefighter entrapment avoidance: modelling evacuation triggers. Int $\mathrm{J}$ Wildl Fire. 2013;22(7):883-893. doi: 10.1071/WF12160

47. Fuentes-Fernández R, Guijarro M, Pajares G. A multi-agent system architecture for sensor networks. Sensors. 2009;9(12):10244-10269. doi: 10. $3390 / \mathrm{s} 91210244$

48. Galdorisi G, Goshorn R. Maritime domain awareness: the key to maritime security operational challenges and technical solutions. In: 11th ICCRTS: Coalition Command and Control in the Networked Era. 2005. http://dodccrp.org/events/11th_ICCRTS/html/papers/043.pdf. Accessed July 23, 2019.

49. Ganz A, Schafer JM, Tang J, et al. Urban search and rescue situational awareness using DIORAMA Disaster Management System. Procedia Eng. 2015;107:349-356. doi: 10.1016/j.proeng.2015.06.091

50. Gao L, Song C, Gao Z, et al. Quantifying information flow during emergencies. Sci Rep. 2014;4:42-44. doi: 10.1038/srep03997

51. Gao Y, Wang H, Li G, et al. Landslide disaster mitigation in Three Gorges Reservoir, China. Science. 2009;30(2):497-517. doi: 10.1007/978-3-64200132-1

52. García M, Saatchi S, Casas A, et al. Extrapolating forest canopy fuel properties in the California Rim fire by combining airborne LiDAR and landsat OLI data. Remote Sens. 2017;9(4):1-18. doi: 10.3390/rs9040394

53. Garcia M, Saatchi S, Casas A, et al. Quantifying biomass consumption and carbon release from the California Rim fire by integrating airborne LiDAR and Landsat OLI data. J Geophys Res Biogeosci. 2017;122(2):340353. doi: $10.1002 / 2015$ JG003315

54. Gargaro D, Rainieri C, Fabbrocino G. Structural and seismic monitoring of the "cardarelli" Hospital in Campobasso. Procedia Eng. 2017;199:936941. doi: 10.1016/j.proeng.2017.09.244

55. Gargees R, Morago B, Pelapur R, et al. Incident-supporting visual cloud computing utilizing software-defined networking. IEEE Trans Circuits Syst Video Technol. 2017;27(1):182-197. doi: 10.1109/TCSVT.2016. 2564898

56. Antonini K, Langer M, Farid A, et al. SWEET CubeSat - water detection and water quality monitoring for the 21st century. Acta Astronaut. 2017;140:10-17. doi: 10.1016/j.actaastro.2017.07.046

57. Gavidia JV. A model for enterprise resource planning in emergency humanitarian logistics. J Humanit Logist Supply Chain Manag. 2017;7(3):246-265. doi: 10.1108/JHLSCM-02-2017-0004

58. Gillis J, Calyam P, Bartels A, et al. Panacea's glass: mobile cloud framework for communication in mass casualty disaster triage. Proc -2015 3rd IEEE Int Conf Mob Cloud Comput Serv Eng MobileCloud 2015 . 2015:128134. doi: 10.1109/MobileCloud.2015.39

59. Giridhar P, Lee J, Abdelzaher T, et al. The event tracking dashboard: from multilingual social media feeds to event patterns and anomalies. In: Proc SPIE. Vol 10653. 2018. doi: 10.1117/12.2306712

60. Glotzbach RJ, Mordkovich DA, Kellogg LD, et al. Work in progress - gap analysis visualization application for geographic representation of statistical data. Proc - Front Educ Conf FIE. 2007:3-4. doi: 10.1109/FIE.2007. 4418049

61. Gonzalez AR, Amber SH. Recent field experiments with commercial satellite imagery direct downlink. J Emerg Manag. 2017;15(1):62-66. doi: $10.5055 / \mathrm{jem} .2017 / 0313$

62. Gorlatova M, Kinget P, Kymissis I, et al. Challenge: ultra-low-power energy-harvesting active networked tags (EnHANTs). Proc Annu Int Conf Mob Comput Networking, MOBICOM. 2009:253-260. doi: 10. $1145 / 1614320.1614348$

63. Gorlatova M, Kinget P, Kymissis I, et al. Energy harvesting active networked tags (EnHANTs) for ubiquitous object networking. IEEE Wirel Commun. 2010;17(6):18-25. doi: 10.1109/MWC.2010. 5675774
64. Gray AJG, Sadler J, Kit O, et al. A semantic sensor web for environmental decision support applications. Sensors. 2011;11(9):8855-8887. doi: $10.3390 / \mathrm{s} 110908855$

65. Greco L, Ritrovato P, Xhafa F. An edge-stream computing infrastructure for real-time analysis of wearable sensors data. Futur Gener Comput Syst. 2019;93:515-528. doi: 10.1016/j.future.2018.10.058

66. Gross IT, Coughlin RF, Cone DC, et al. GPS devices in a simulated mass casualty event. Prehosp Emerg Care. 2019;23(2):290-295. doi: 10.1080/ 10903127.2018.1489018

67. Aracri S, Borghini M, Canesso D, et al. Trials of an autonomous profiling buoy system. J Oper Oceanogr. 2016;9(Suppl 1):s176-s184. doi: 10.1080/ 1755876X.2015.1115631

68. Haddawy P, De Felice G, Frommberger L, et al. Situation awareness in crowdsensing for disease surveillance in crisis situations. ACM Int Conf Proceeding Ser. 2015;15. doi: 10.1145/2737856.2737879

69. Hamilton MK, Kramer MJ, Feddes RG, et al. Sensor integration architectures for homeland security. Proc SPIE. 2002;4745:74-85. doi: 10.1117/ 12.475858

70. Hanken T, Young S, Smilowitz K, et al. Developing a data visualization system for the Bank of America Chicago Marathon (Chicago, Illinois USA). Prehosp Disaster Med. 2016;31(5):572-577. doi: 10.1017/ S1049023X1600073X

71. Harris AE, Hopkinson L, Soeder DJ. Developing monitoring plans to detect spills related to natural gas production. Environ Monit Assess. 2016;188(11):647. doi: 10.1007/s10661-016-5641-4

72. Hartanto IM, Almeida C, Alexandridis TK, et al. Merging earth observation data, weather predictions, in-situ measurements, and hydrological models, for water information services. Environ Eng Manag J. 2015;14(9):2151895. doi: 10.30638/eemj.2015.218

73. Hassanzadeh A, Stoleru R, Shihada B. Energy efficient monitoring for intrusion detection in battery-powered wireless mesh networks. Lect Notes Comput Sci (including Subser Lect Notes Artif Intell Lect Notes Bioinformatics). 2011;6811 LNCS:44-57. doi: 10.1007/978-3-64222450-8_4

74. He Q, Fok HS, Chen Q, et al. Water level reconstruction and prediction based on space-borne sensors: a case study in the Mekong and Yangtze river basins. Sensors (Basel). 2018;18(9):3076. doi: 10.3390/s18093076

75. Heard J, Thakur S, Losego J, et al. Big board: teleconferencing over maps for shared situational awareness. Comput Support Coop Work CSCW An Int J. 2014;23(1):51-74. doi: 10.1007/s10606-013-9191-9

76. Hill DJ, Liu Y, Marini L, et al. A virtual sensor system for user-generated, real-time environmental data products. Environ Model Softw. 2011;26(12):1710-1724. doi: 10.1016/j.envsoft.2011.09.001

77. Hohil ME, Desai S, Morcos A. Implementation of algorithms to discriminate chemical/biological airbursts from high explosive airbursts utilizing acoustic signatures. Chem Biol Sens VII. 2006;6218(May 2006):62180X. doi: $10.1117 / 12.667876$

78. Arco E, Ajmar A, Arneodo F, et al. An operational framework to integrate traffic message channel (TMC) in emergency mapping services (EMS). Eur J Remote Sens. 2017;50(1):478-495. doi: 10.1080/22797254. 2017.1361306

79. Hormati M, Belqasmi F, Glitho R, et al. A DNS protocol-based service discovery architecture for disaster response systems. Proc - Int Symp Comput Commun. 2013:366-371. doi: 10.1109/ISCC.2013.6754974

80. Hosseini M, Salehi MA, Gottumukkala R. Enabling interactive video streaming for public safety monitoring through batch scheduling. In: 2017 IEEE 19th Intl Conference on High Performance Computing and Communications, 2017 IEEE 15th Intl Conference on Smart City, SmartCity 2017 and 2017 IEEE 3rd Intl Conference on Data Science and Systems. 2018:474-481. doi: 10.1109/HPCC-SmartCity-DSS.2017.62

81. Houser C, Bishop MP, Barrineau P. Characterizing instability of aeolian environments using analytical reasoning. Earth Surf Process Landforms. 2015;40(5):696-705. doi: 10.1002/esp.3679

82. Howden EA, Brendley K. Networked sensors for the objective force. Unattended Gr Sens Technol Appl IV. 2002;4743(August 2002):260. doi: $10.1117 / 12.448522$ 
83. Hsu PH, Wu SY, Lin FT. Disaster management using GIS technology: a case study in Taiwan. In: Asian Association on Remote Sensing - 26th Asian Conference on Remote Sensing and 2nd Asian Space Conference, ACRS 2005. Vol 3. 2005:1510-1519.

84. Iland D, Voita D, Belding E. Delay tolerant disaster communication with the One Laptop per Child XO laptop. In: ISCRAM 2013 Conference Proceedings - 10th International Conference on Information Systems for Crisis Response and Management. 2013:863-867.

85. Isikdag U, Underwood J, Aouad G, et al. Investigating the role of building information models as a part of an integrated data layer: a fire response management case. Archit Eng Des Manag. 2007;3(2):124-142. doi: 10. 1080/17452007.2007.9684636

86. Jafarzadeh RS. Emergency management 2.0: integrating social media in emergency communications. J Emerg Manag. 2011;9(4):13-18. doi: 10. 5055/jem.2011.0063

87. Jain T, Sibley A, Stryhn H, et al. Comparison of unmanned aerial vehicle technology versus standard practice in identification of hazards at a mass casualty incident scenario by primary care paramedic students. Disaster Med Public Health Prep. 2018;12(5):631-634. doi: 10.1017/dmp.2017.129

88. James JJ, Lyznicki JM, Irmiter C, et al. Secure personal health information system for use in disasters and public health emergencies. Internet-Based Intell Public Heal Emergencies Early Detect Response Dis Outbreak Cris. 2013:113-125. doi: 10.3233/978-1-61499-175-5-113

89. Arnous MO. Integrated remote sensing and GIS techniques for landslide hazard zonation: a case study Wadi Watier area, South Sinai, Egypt. J Coast Conserv. 2011;15(4):477-497. doi: 10.1007/s11852-010-0137-9

90. Jokela J, Rådestad M, Gryth D, et al. Increased situation awareness in major incidents'radio frequency identification (RFID) Technique: a promising tool. Prehosp Disaster Med. 2012;27(1):81-87. doi: 10.1017/ S1049023X12000295

91. Jones AS, Horsburgh JS, Reeder SL, et al. A data management and publication workflow for a large-scale, heterogeneous sensor network. Environ Monit Assess. 2015;187(6). doi: 10.1007/s10661-015-4594-3

92. Joseph SL, Xiao J, Zhang X, et al. Being aware of the world: toward using social media to support the blind with navigation. IEEE Trans HumanMachine Syst. 2015;45(3):399-405. doi: 10.1109/THMS.2014.2382582

93. Kabou A, Nouali-Taboudjemat N, Nouali O. Toward a new backpressure-based framework to enhance situational awareness in disaster response. In: Proceedings of the 2017 4th International Conference on Information and Communication Technologies for Disaster Management, ICT-DM 2017. 2018. doi: 10.1109/ICT-DM.2017.8275678

94. Kakooei M, Baleghi Y. Fusion of satellite, aircraft, and UAV data for automatic disaster damage assessment. Int J Remote Sens. 2017;38 (8-10):2511-2534. doi: 10.1080/01431161.2017.1294780

95. Kamiński Ł, Kulawiak M, Cizmowski W, et al. Web-based GIS dedicated for marine environment surveillance and monitoring. Ocean 'O9 IEEE Bremen Balanc Technol with Futur Needs. 2009. doi: 10.1109/OCEANSE. 2009.5278151

96. Kaniyantethu S. FIRESTORM: a collaborative network suite application for rapid sensor data processing and precise decisive responses. Unattended Ground, Sea, Air Sens Technol Appl XIII. 2011;8046(May 2011):80460I. doi: $10.1117 / 12.888931$

97. Karagiannidis L, Misichroni F, Damigos Y, et al. A novel and interoperable communication gateway implementation for evacuation systems. 2016 Int Wirel Commun Mob Comput Conf IWCMC 2016. 2016:10451050. doi: 10.1109/IWCMC.2016.7577203

98. Karkkainen AP. Improving situation awareness using a hub architecture for friendly force tracking. Cyber Secur Situat Manag Impact Assess II; Vis Anal Homel Def Secur II. 2010;7709(April 2010):770905. doi: 10.1117/ 12.852627

99. Karnatak HC, Shukla R, Sharma VK, et al. Spatial mashup technology and real time data integration in geo-web application using open source GIS - a case study for disaster management. Geocarto Int. 2012;27(6):499514. doi: $10.1080 / 10106049.2011 .650651$

100. Ashish N, Eguchi R, Hegde R, et al. Situational awareness technologies for disaster response. In: Terrorism Informatics: Knowledge Management and
Data Mining for Homeland Security, 2008:517-544. doi: 10.1007/978-0. 387-71613-8_24

101. Karstens CD, Correia J, LaDue DS, et al. Development of a humanmachine mix for forecasting severe convective events. Weather Forecast. 2018;33(3):715-737. doi: 10.1175/WAF-D-17-0188.1

102. Kassab A, Liang S, Gao Y. Real-time notification and improved situational awareness in fire emergencies using geospatial-based publish/subscribe. Int J Appl Earth Obs Geoinf. 2010;12(6):431-438. doi: 10.1016/ j.jag.2010.04.001

103. Kaufhold M-A, Rupp N, Reuter C, et al. 112. Social: design and evaluation of a mobile crisis app for bidirectional communication between emergency services and citizens. In: Twenty-Sixth European Conference on Information Systems (ECIS2018). 2018.

104. Kavitha T, Saraswathi S. Smart technologies for emergency response and disaster management: new sensing technologies or/and devices for emergency response and disaster management. Smart Technol Emerg Response Disaster Manag. 2017:1-39. doi: 10.4018/978-1-5225-2575-2.ch001

105. Kawasaki A, Koudelova P, Tamakawa K, et al. Data integration and analysis system (DIAS) as a platform for data and model integration: cases in the field of water resources management and disaster risk reduction. Data Sci J. 2018;17(Rcuk 2010):1-14. doi: 10.5334/dsj-2018-029

106. Kaya Y, Ventura C. British Columbia Smart Infrastructure Monitoring System (BCSIMS). In: 10th International Workshop on Structural Health Monitoring. 2015:1600-1607.

107. Kent JD, Dokka RK. A spatially accurate incident reporting system during the 2010 Gulf of Mexico oil spill disaster. J Emerg Manag. 2011;9(4):69-79. doi: 10.5055/jem.2011.0068

108. Keskisarkka R. Semantic complex event processing for decision support. In: ISWC 2014, Part II, LNCS. Vol 8797. 2014:529-536.

109. Kiltz L, Smith R. Experimenting with GIS in doing damage assessments: a trial run at disaster city. J Homel Secur Emerg Manag. 2011;8(1). doi: 10. 2202/1547-7355.1853

110. Kim GH, Nam JC, Mahmud I, et al. Multi-drone control and network self-recovery for flying Ad Hoc Networks. Int Conf Ubiquitous Futur Networks, ICUFN. 2016;2016-Augus:148-150. doi: 10.1109/ICUFN. 2016.7537004

111. Ashish N, Mehrotra S. Community driven data integration for emergency response. In: ISCRAM 2010 - 7th International Conference on Information Systems for Crisis Response and Management: Defining Crisis Management 3.0, Proceedings. 2010.

112. Kim HS, Chung CK. Development and application of gis-based information system of landslide hazard map induced by Earthquakes and rainfall in Korea. GISTAM 2016 - Proc 2nd Int Conf Geogr Inf Syst Theory, Appl Manag. 2016;(Gistam):227-235. doi: 10.5220/0005866802270234

113. Klager G. Networked sensors for the combat forces. Unmanned/ Unattended Sensors Sens Networks. 2004;5611(November 2004):204. doi: $10.1117 / 12.581617$

114. Kocev I, Achkoski J, Bogatinov D, et al. Novel approach for automating medical emergency protocol in military environment. Technol Heal Care. 2018;26(2):249-261. doi: 10.3233/THC-170852

115. Kohn M, Galanti E, Price C, et al. Nowcasting thunderstorms in the Mediterranean region using lightning data. Atmos Res. 2011;100(4):489-502. doi: 10.1016/j.atmosres.2010.08.010

116. Kopylec J, D'Amico A, Goodall J. Visualizing cascading failures in critical cyber infrastructures. In: IFIP Advances in Information and Communication Technology. Vol 253. 2008:351-364.

117. Kostkova P, Garbin S, Moser J, et al. Integration and visualization public health dashboard: the medi+board pilot project. WWW 2014 Companion - Proc 23rd Int Conf World Wide Web. 2014:657-662. doi: 10.1145/ 2567948.2579276

118. Kozlovszky M, Pavlinic DZ. Environment and situation monitoring for firefighter teams. CINTI 2014 - 15th IEEE Int Symp Comput Intell Informatics, Proc. 2014:439-442. doi: 10.1109/CINTI.2014.7028715

119. Krawiec B, Kochersberger K, Conner DC. Autonomous aerial radio repeating using an a-based path planning approach. J Intell Robot Syst Theory Appl. 2014;74(3-4):769-789. doi: 10.1007/s10846-013-9853-3 
120. Kroutil RT, Shen SS, Lewis PE, et al. Airborne remote sensing for Deepwater Horizon oil spill emergency response. Imaging Spectrom XV. 2010;7812(August 2010):78120E. doi: 10.1117/12.863258

121. Kryvasheyeu Y, Chen H, Obradovich N, et al. Rapid assessment of disaster damage using social media activity. Sci Adv. 2016;2(3):1-12. doi: 10. 1126/sciadv. 1500779

122. Aulov O, Halem M. Human sensor networks for improved modeling of natural disasters. Proc IEEE. 2012;100(10):2812-2823. doi: 10.1109/ JPROC.2012.2195629

123. Kumar S, Rangan PV, Ramesh MV. Design and validation of wireless communication architecture for long term monitoring of landslides. 4th World Landslide Forum Adv Cult Living with Landslides. 2017:51-60. doi: 10.1007/978-3-319-53487-9

124. Kussul N, Shelestov A, Skakun S, et al. Service-oriented infrastructure for flood mapping using optical and SAR satellite data. Int J Digit Earth. 2014;7(10):829-845. doi: 10.1080/17538947.2013.781242

125. La Loggia G, Arnone E, Ciraolo G, et al. An integrated information system for the acquisition, management and sharing of environmental data aimed to decision making. Remote Sens Agric Ecosyst Hydrol XIV. 2012;8531(October 2012):853112. doi: 10.1117/12.976300

126. La Salla LM, Odubela A, Espada G, et al. The EDNA public safety drone: bullet-stopping lifesaving. GHTC 2018 - IEEE Glob Humanit Technol Conf Proc. 2019:1-8. doi: 10.1109/GHTC.2018.8601597

127. Labbé P, Arden D, Li L. GPS-INS-radio and GIS integration into handheld computers for disperse civilian and military urban operations. In: Proceedings of the Institute of Navigation, National Technical Meeting. Vol 2; 2007:998-1010.

128. Lagios E, Sideris G, Zervos F, et al. Tectonic early warning system through real-time radon $(\mathrm{Rn})$ monitoring: preliminary results of a geophysical method for forecasting earthquakes. In: Earthquake Hazard and Seismic Risk Reduction. 2000:261-270.

129. Lambrigtsen B. Observing fast mesoscale atmospheric processes with a geostationary microwave sounder. In: Proc SPIE. Vol 10776; 2018. doi: $10.1117 / 12.2324048$

130. Lara-Cueva R, Benítez D, Caamaño A, et al. Performance evaluation of a volcano monitoring system using wireless sensor networks. In: 2014 IEEE Latin-America Conference on Communications (IEEE LATINCOM). 2014. doi: 10.1109/LATINCOM.2014.7041853

131. Lara R, Benítez D, Caamaño A, et al. On real-time performance evaluation of volcano-monitoring systems with wireless sensor networks. IEEE Sens J. 2015;15(6):3514-3523. doi: 10.1109/JSEN.2015.2393713

132. Larochelle B, Kruijff GJM, Smets NJJM, et al. Experiences with USAR mobile interfaces: the need for persistent geo-localized information. IEEE Int Conf Intell Robot Syst. 2013:5333-5338. doi: 10.1109/IROS.2013. 6697128

133. Avvenuti M, Cresci S, Del Vigna F, et al. CrisMap: a big data crisis mapping system based on damage detection and geoparsing. Inf Syst Front. 2018;20(5):993-1011. doi: 10.1007/s10796-018-9833-z

134. Lenert LA, Kirsh D, Griswold WG, et al. Design and evaluation of a wireless electronic health records system for field care in mass casualty settings. J Am Med Inform Assoc. 2011;18(6):842-852. doi: 10.1136/ amiajnl-2011-000229

135. Lezama N. Evaluation of a cell phone-based mobile medical documentation system during Operation Black Swan. Ann Emerg Med. 2013;62(4): S16. doi: 10.1016/j.annemergmed.2013.07.325

136. Lizotte TE. Dynamic 3D visual analytic tools: a method for maintaining situational awareness during high tempo warfare or mass casualty operations. Cyber Secur Situat Manag Impact Assess II; Vis Anal Homel Def Secur II. 2010;7709(April 2010):770912. doi: 10.1117/12.855909

137. Losier L-M, Grael FF, Desgagne E, et al. Cloud-based alert system for aggressive natural disasters. From Fundam To Appl Geotech. 2015:31593166. doi: 10.3233/978-1-61499-603-3-3159

138. Lundberg CL, Sevil HE, Das A. A VisualSfM based rapid 3-D modeling framework using swarm of UAVs. 2018 Int Conf Unmanned Aircr Syst ICUAS 2018. 2018:22-29. doi: 10.1109/ICUAS.2018.8453396
139. Lurio J, Morrison FP, Pichardo M, et al. Using electronic health record alerts to provide public health situational awareness to clinicians. J Am Med Inform Assoc. 2010;17(2):217-219. doi: 10.1136/jamia.2009.000539

140. Lynch RA, Smith T, Jacobs MC, et al. A radiation weather station: development of a continuous monitoring system for the collection, analysis, and display of environmental radiation data. Health Phys. 2018;115(5):590-599. doi: 10.1097/HP.0000000000000962

141. Maffei AR, Lerner S, Lynch J, et al. ExView: a real-time collaboration environment for multi-ship experiments. In: IEEE OCEANS 2007 Europe; 2007.

142. Maltsev SA, Stepanov M V. Alarm-Seismo 3 automated monitoring station. Seism Instruments. 2009;45(1):95-104. doi: 10.3103/s074792390 9010174

143. Mandl D, Frye S, Cappelaere P, et al. Use of the earth observing one (EO-1) satellite for the namibia sensorweb flood early warning pilot. IEEE J Sel Top Appl Earth Obs Remote Sens. 2013;6(2):298-308. doi: 10.1109/JSTARS.2013.2255861

144. Abrajano G, Favila C, Luo CY, et al. Demonstrations of post-disaster resilient communications and decision-support platform with UAVs, ground teams and vehicles using delay-tolerant information networks on sub-GHz frequencies. GHTC 2017 - IEEE Glob Humanit Technol Conf Proc. 2017;2017-Janua:1-8. doi: 10.1109/GHTC.2017.8239327

145. Avvenuti M, Del Vigna F, Cresci S, et al. Pulling Information from social media in the aftermath of unpredictable disasters. Proc 2015 2nd Int Conf Inf Commun Technol Disaster Manag ICT-DM 2015. 2016:258-264. doi: 10.1109/ICT-DM.2015.7402058

146. Marecki J, Schurr N, Tambe M, et al. Safety and security in multiagent systems. 2009;4324(September 2009). doi: 10.1007/978-3-642-04879-1

147. McCurdy NJ, Griswold WG, Lenert LA. RealityFlythrough: enhancing situational awareness for medical response to disasters using ubiquitous video. In: AMIA Annual Symposium Proceedings/AMIA Symposium. 2005:510-514.

148. Minor CP, Johnson KJ, Rose-Pehrsson SL, et al. A full-scale prototype multisensor system for fire detection and situational awareness. Multisensor, Multisource Inf Fusion Archit Algorithms. 2007;6571(April 2007):65710E. doi: 10.1117/12.719764

149. Mohsin B, Steinhäusler F, Madl P, et al. An innovative system to enhance situational awareness in disaster response: what are end users looking for in such systems. J Homel Secur Emerg Manag. 2016;13(3):301-327. doi: 10.1515/jhsem-2015-0079

150. Naser MZ, Kodur VKR. Cognitive infrastructure - a modern concept for resilient performance under extreme events. Autom Constr. 2018;90(March):253-264. doi: 10.1016/j.autcon.2018.03.004

151. Negi I, Tsow F, Tanwar K, et al. Novel monitor paradigm for real-time exposure assessment. J Expo Sci Environ Epidemiol. 2011;21(4):419-426. doi: $10.1038 /$ jes.2010.35

152. Nekoogar F, Dowla F. Location-based tracking using long-range passive RFID and ultrawideband communications. Multimed Content Mob Devices. 2013;8667(March 2013):86670M. doi: 10.1117/12.2008706

153. Nikolakopoulos K, Kavoura K, Depountis N, et al. Preliminary results from active landslide monitoring using multidisciplinary surveys. Eur J Remote Sens. 2017;50(1):280-299. doi: 10.1080/22797254.2017. 1324741

154. Nogueira ML, Greis NP. Application of answer set programming for public health data integration and analysis. Lect Notes Comput Sci (including Subser Lect Notes Artif Intell Lect Notes Bioinformatics). 2011;6908 LNCS:118-134. doi: 10.1007/978-3-642-23300-5_10

155. Nunavath V, Prinz A. Data sources handling for emergency management: supporting information availability and accessibility for emergency responders. 19th Int Conf HCI Int 2017, Proceedings, Part II, LNCS. 2017;10274:240-259. doi: 10.1007/978-3-319-58524-6

156. Backfried G, Kais I, Quirchmayr G. Towards a generic data-model for cross-media communication during disasters $\&$ crises proposed framework for classification of platforms and technologies. Proc 2016 3rd Int Conf Inf Commun Technol Disaster Manag ICT-DM 2016. 2017. doi: 10.1109/ ICT-DM.2016.7857228 
157. Nyarku M, Mazaheri M, Jayaratne R, et al. Mobile phones as monitors of personal exposure to air pollution: is this the future? PLoS One. 2018;13(2):1-18. doi: 10.1371/journal.pone.0193150

158. Oh PY, Joyce M, Gallagher J. Designing an aerial robot for hoverand-stare surveillance. 2005 Int Conf Adv Robot ICAR '05, Proc. 2005;2005(August 2005):303-306. doi: 10.1109/ICAR.2005.1507428

159. Oliveira ACM, Botega LC, Saran JF, et al. Crowdsourcing, data and information fusion and situation awareness for emergency management of forest fires: the project DF100Fogo (FDWithoutFire). Comput Environ Urban Syst. 2017. doi: 10.1016/j.compenvurbsys.2017.08.006

160. Onorati T, Diaz P. Semantic Visualization of Twitter Usage in Emergency and Crisis Situations. ISCRAM-med 2015 Lect Notes Bus Inf Process. 2015;233:3-14. doi: 10.1007/978-3-319-24399-3

161. Overby D, Wall J, Keyser J. Interactive analysis of situational awareness metrics. Vis Data Anal 2012. 2012;8294(January 2012):829406. doi: 10. $1117 / 12.905187$

162. Oxfam. A long way to go. The Ebola response in West Africa at the sixty day mark. Oxfam. https://policy-practice.oxfam.org.uk/publications/along-way-to-go-the-ebola-response-in-west-africa-at-the-sixty-day-mark336919. Published December 9, 2014. Accessed July 23, 2019.

163. Paciello R, Coviello I, Bitonto P, et al. An innovative system for sharing, integration and visualization of heterogeneous 4D-information. Environ Model Softw. 2016;77:50-62. doi: 10.1016/j.envsoft.2015.11.011

164. Patton RM, Steed CA, Stahl CG, et al. Observing community resiliency in social media. Lect Notes Comput Sci (including Subser Lect Notes Artif Intell Lect Notes Bioinformatics). 2013;7975 LNCS(PART 5):491-501. doi: 10.1007/978-3-642-39640-3_36

165. Peña-Mora F, Thomas JK, Golparvar-Fard M, et al. Supporting civil engineers during disaster response and recovery using a segway mobile workstation chariot. J Comput Civ Eng. 2012;26(3):448-455. doi: 10.1061/ (ASCE)CP

166. Pfeifer B, Wurz M, Hanser F, et al. An epidemiological modeling and data integration framework. Methods Inf Med. 2010;3:290-296. doi: 10.3414/ ME09-02-0025

167. Backfried G, Schmidt C, Aniola D, et al. A general framework for using social and traditional media during natural disasters: QuOIMA and the Central European Floods of 2013. Fusion Methodol Cris Manag High Lev Fusion Decis Mak. 2016:469-487. doi: 10.1007/978-3-319-22527-2

168. Pfeiffenberger T, Dorfinger P, Von Tüllenburg F. Communication coverage awareness for self-aligning wireless communication in disaster operations. 2015 IEEE Int Conf Pervasive Comput Commun Work PerCom Work 2015. 2015:481-486. doi: 10.1109/PERCOMW.2015.7134085

169. Plana Q, Alferes J, Fuks K, et al. Towards a water quality database for raw and validated data with emphasis on structured metadata. Water Qual Res J Canada. 2019;54(1):1-9. doi: 10.2166/WQRJ.2018.013

170. Porter K, Hellman S, Hortacsu A. FEMA ROVER Version 2 and ROVER ATC-20, Mobile Earthquake Safety Software. In: Improving the Seismic Performance of Existing Buildings and Other Structures. 2015:787-796.

171. Prasanna R, Yang L, King M, et al. Information systems architecture for fire emergency response. J Enterp Inf Manag. 2017;30(4):605-624. doi: 10. 1108/JEIM-12-2015-0120

172. Preece A, Roberts C, Rogers D, et al. From open source communications to knowledge. Next-Generation Anal IV. 2016;9851(May 2016):98510K. doi: $10.1117 / 12.2224533$

173. Pringle C. From curiosity to collaboration: leveraging technology to improve situational awareness. Safeguarding Homel Secur. 2009:159-176. doi: 10.1007/978-1-4419-0371-6

174. Qin Z, Do N, Denker G, et al. Software-defined cyber-physical multinetworks. 2014 Int Conf Comput Netw Commun ICNC. 2014:322-326. doi 10.1109/ICCNC.2014.6785354

175. Qureshi WS, Ekpanyapong M, Dailey MN, et al. QuickBlaze: early fire detection using a combined video processing approach. Fire Technol. 2016;52(5):1293-1317. doi: 10.1007/s10694-015-0489-7

176. Racette MP, Smith CT, Cunningham MP, et al. Improving situational awareness for humanitarian logistics through predictive modeling.
2014 IEEE Syst Inf Eng Des Symp SIEDS 2014. 2014;00(c):334-339. doi: $10.1109 /$ SIEDS.2014.6829918

177. Ramchurn SD, Huynh TD, Wu F, et al. A disaster response system based on human-agent collectives. J Artif Intell Res. 2016;57:661-708. doi: 10. 1613/jair.5098

178. Bader A, Alouini MS. Mobile ad hoc networks in bandwidth-demanding mission-critical applications: practical implementation insights. IEEE Access. 2017;5:891-910. doi: 10.1109/ACCESS.2016.2614329

179. Raskob W, Gers E, Meyer Zu Drewer P, et al. SECURITY2People - functionality of the final demonstrator. Commun Comput Inf Sci. 2012;318 CCIS:81-84. doi: 10.1007/978-3-642-33161-9_14

180. Ribeiro C, Mavaddat F, Ferworn A. Adaptive engineering of an embedded system, engineered for use by search and rescue canines. Syst Cybern Informatics. 2011;9(3):41-49.

181. Roberts G, Woolfenden E. The application of thermal desorption for the analysis of trace toxic compounds in areas of human occupation. In: Proceedings: Indoor Air 2005:3859-3863.

182. Rodzi MZM, Zakaria NH, Ahmad MN. FloodFeed: an ontology-based data feed for flood sensor knowledge integration. In: Knowledge Management International Conference (KMICe) 2014. 2014:249-254.

183. Ronchetti F, Corsini A, Kollarits S, et al. Improve information provision for disaster management: MONITOR II, EU project. Landslide Sci Pract Soc Econ Impact Policies. 2013;7:47-54. doi: 10.1007/978-3-64231313-4-7

184. Roth LH, Criss K, Stewart X, et al. Preplink: a novel web-based tool for healthcare emergency planning and response. Biosecur Bioterror. 2009; 7(1):85-92. doi: 10.1089/bsp.2008.0052

185. Ruth T, Audersch S, Kluge S, et al. From sensor to situational awareness. Ocean 2016 MTS/IEEE Monterey, OCE 2016. 2016;(03):1-8. doi: 10. 1109/OCEANS.2016.7761249

186. Sahay A, Kumar AA, Pongpaichet S, et al. Multimedia rescue systems for floods. 9th Int Conf Manag Digit Ecosyst MEDES 2017. 2017:210-215. doi: $10.1145 / 3167020.3167052$

187. Sahin YG, Ince T. Early forest fire detection using radio-acoustic sounding system. Sensors. 2009;9(3):1485-1498. doi: 10.3390/s90301485

188. Sakai T, Tamura K, Kitakami H. Emergency situation awareness during natural disasters using density-based adaptive spatiotemporal clustering. Lect Notes Comput Sci (including Subser Lect Notes Artif Intell Lect Notes Bioinformatics). 2015;9052:155-169. doi: 10.1007/978-3-319-22324-7

189. Bahrepour M, Meratnia N, Poel M, et al. Distributed event detection in wireless sensor networks for disaster management. Proc - 2nd Int Conf Intell Netw Collab Syst INCOS 2010. 2010:507-512. doi: 10.1109/ INCOS.2010.24

190. Saleem HM, Xu Y, Ruths D. Novel situational information in mass emergencies: what does twitter provide? Procedia Eng. 2014;78:155-164. doi: 10.1016/j.proeng.2014.07.052

191. Salfinger A, Schwinger W, Retschitzegger W, et al. Mining the disaster hotspots - Situation-adaptive crowd knowledge extraction for crisis management. 2016 IEEE Int Multi-Disciplinary Conf Cogn Methods Situat Aware Decis Support CogSIMA 2016. 2016:212-218. doi: 10.1109/ COGSIMA.2016.7497812

192. Santamaria E, Moßgraber J, Brill E, et al. A system architecture for the detection and mitigation of CBRN related contamination events of drinking water. Procedia Eng. 2015;119(1):319-327. doi: 10.1016/j. proeng.2015.08.891

193. Scanlon M V. Acoustic sensors in the helmet detect voice and physiology. Sensors, Command Control Commun Intell Technol Homel Def Law Enforc II. 2003;5071(September 2003):41. doi: 10.1117/12.486064

194. Schurr N, Marecki J, Tambe M, et al. Towards flexible coordination of human-agent teams. Multiagent Grid Syst. 2005;1(1):3-16. doi: 10.3233/ MGS-2005-1102

195. Serban O, Thapen N, Maginnis B, et al. Real-time processing of social media with SENTINEL: a syndromic surveillance system incorporating deep learning for health classification. Inf Process Manag. 2019;56(3):1166-1184. doi: 10.1016/j.ipm.2018.04.011 
196. Shapiro JS, Genes N, Kuperman G, et al. Health information exchange, biosurveillance efforts, and emergency department crowding during the spring 2009 H1N1 outbreak in New York City. Ann Emerg Med. 2010;55(3):274-279. doi: 10.1016/j.annemergmed.2009.11.026

197. Sharma RK, Lavrenko A, Kolb D, et al. Cognitive scout node for communication in disaster scenarios. J Comput Networks Commun. 2012;2012. doi: 10.1155/2012/160327

198. Shen SS, Lewis PE. Deepwater Horizon oil spill monitoring using airborne multispectral infrared imagery. Algorithms Technol Multispectral, Hyperspectral, Ultraspectral Imag XVII. 2011;8048(May 2011):80480H. doi: $10.1117 / 12.887055$

199. Shoureshi RA, Shen AQ. Design of a biomimetic-based monitoring and diagnostic system for civil structures. Int J Nanotechnol. 2007;4(3):309. 324. doi: 10.1504/IJNT.2007.013568

200. Bakon M, Perissin D, Lazecky M, et al. Infrastructure non-linear deformation monitoring via satellite radar interferometry. Procedia Technol. 2014;16:294-300. doi: 10.1016/j.protcy.2014.10.095

201. Simon T, Goldberg A, Aharonson-Daniel L, et al. Twitter in the cross fire - the use of social media in the Westgate Mall terror attack in Kenya. PLoS One. 2014;9(8):e104136. doi: 10.1371/journal.pone.0104136

202. Skinnemoen H. UAV \& satellite communications live missioncritical visual data. Proceeding - ICARES 2014 IEEE Int Conf Aerosp Electron Remote Sens Technol. 2014:12-19. doi: 10.1109/ICARES.2014. 7024391

203. Smirnov A, Levashova T, Shilov N, et al. Decision support for wide area disasters. Fusion Methodol Cris Manag. 2016:519-537. doi: 10.1007/9783-319-22527-2

204. Smirnov A, Shilov N, Levashova T, et al. Web-service network for disaster management. In: Proceedings of ISCRAM 2008 - 5th International Conference on Information Systems for Crisis Response and Management. 2008:516-525.

205. Song R, Brown JD, Tang H, et al. Secure and efficient routing by Leveraging Situational Awareness Messages in tactical edge networks. 2015 Int Conf Mil Commun Inf Syst ICMCIS. 2015. doi: 10.1109/ ICMCIS.2015.7158713

206. Steinberg M. Intelligent autonomy for unmanned naval systems. Unmanned Syst Technol VIII. 2006;6230(May 2006):623013. doi: 10. $1117 / 12.665870$

207. Su WR, Huang CH, Wu SY, et al. Disaster prevention and rescue information service platforms. Int J Autom Smart Technol. 2011;1(2):63-71. doi: 10.5875/ausmt.v1i2.128

208. Sung WT, Chung HY. A distributed energy monitoring network system based on data fusion via improved PSO. Meas J Int Meas Confed. 2014;55:362-374. doi: 10.1016/j.measurement.2014.05.007

209. Surakitbanharn C, Ebert DS. Improving the communication of emergency and disaster information using visual analytics. Adv Intell Syst Comput. 2018;592:143-152. doi: 10.1007/978-3-31960366-7_14

210. Talbot LM, Talbot BG. Fast-responder: rapid mobile-phone access to recent remote sensing imagery for first responders. IEEE Aerosp Conf Proc. 2013:1-10. doi: 10.1109/AERO.2013.6497144

211. Balfour RE, Donnelly BP. The what, why and how of achieving urban telepresence. 9th Annu Conf Long Isl Syst Appl Technol LISAT. 2013. doi: 10.1109/LISAT.2013.6578234

212. Tanzi TJ, Roudier Y, Apvrille L. Towards a new architecture for autonomous data collection. Int Arch Photogramm Remote Sens Spat Inf Sci - ISPRS Arch. 2015;40(3W3):363-369. doi: 10.5194/isprsarchivesXL-3-W3-363-2015

213. Thapen N, Simmie D, Hankin C, et al. DEFENDER: detecting and forecasting epidemics using novel data-analytics for enhanced response. PLoS One. 2016;11(5):1-19. doi: 10.1371/journal.pone.0155417

214. Thomopoulos SCA, Kyriazanos DM, Astyakopoulos A, et al. OCULUS fire: a command and control system for fire management with crowd sourcing and social media interconnectivity. Signal Process Sensor/ Information Fusion, Target Recognit XXV. 2016;9842(May 2016):98420U. doi: $10.1117 / 12.2223996$
215. Tomaszewski B. Situation awareness and virtual globes: applications for disaster management. Comput Geosci. 2011;37(1):86-92. doi: 10.1016/j. cageo.2010.03.009

216. Towler J, Krawiec B, Kochersberger K. Terrain and radiation mapping in post-disaster environments using an autonomous helicopter. Remote Sens. 2012;4(7):1995-2015. doi: 10.3390/rs4071995

217. United States Government Accountability Office. Coast Guard: Observations on the Preparation, Response, and Recovery Missions Related to Hurricane Katrina. 2006. https://www.gao.gov/htext/ d06903.html. Accessed July 23, 2019.

218. US National Park Service: Division of Fire and Aviation. Carr Fire After-Action Review. 2018. https://www.wildfirelessons.net/orphans/ viewincident?DocumentKey=1df73f85-c16f-45bd-8f5e-9fOf22bc4dce. Accessed July 23, 2019.

219. Valcourt SA, Datla P, Chamberlin K, et al. Information integration for public safety officers. Sensors, Command Control Commun Intell Technol Homel Secur Homel Def VII. 2008;6943(April 2008):69430M. doi: 10. $1117 / 12.776874$

220. Vandecasteele F, Merci B, Verstockt S. Fireground location understanding by semantic linking of visual objects and building information models. Fire Saf J. 2017;91(March):1026-1034. doi: 10.1016/j.firesaf. 2017.03.083

221. Vieweg S, Hughes AL, Starbird K, et al. Microblogging during two natural hazards events: what twitter may contribute to situational awareness. Conf Hum Factors Comput Syst - Proc. 2010;2:1079-1088. doi: 10.1145/ 1753326.1753486

222. Baltsavias E, Cho K, Remondino F, et al. Rapidmap - rapid mapping and information dissemination for disasters using remote sensing and geoinformation. Int Arch Photogramm Remote Sens Spat Inf Sci - ISPRS Arch. 2013;40(7W2):31-35. doi: 10.5194/isprsarchives-XL-7-W2-31-2013

223. West A, Mellini M. Remote ballistic emplacement of an electro-optical and acoustic target detection and localization system. Sensors, Command Control Commun Intell Technol Homel Secur Defense, Law Enforc XIV. 2015;9456(May 2015):94560Z. doi: 10.1117/12.2182162

224. Wozniak S, Rossberg M, Schaefer G. Towards trustworthy mobile social networking services for disaster response. 2013 IEEE Int Conf Pervasive Comput Commun Work PerCom Work 2013. 2013;(March):528-533. doi: 10.1109/PerComW.2013.6529553

225. Wu Z, Lei S, Bian Z, et al. Study of the desertification index based on the albedo-MSAVI feature space for semi-arid steppe region. Environ Earth Sci. 2019;78(6):1-13. doi: 10.1007/s12665-019-8111-9

226. Xu Z, Zhang H, Sugumaran V, et al. Participatory sensing-based semantic and spatial analysis of urban emergency events using mobile social media. Eurasip J Wirel Commun Netw. 2016;2016(1):1-9. doi: 10.1186/s13638016-0553-0

227. Yang Z, Schafer J, Ganz A. Disaster response: victims' localization using Bluetooth Low Energy sensors. 2017 IEEE Int Symp Technol Homel Secur HST 2017. 2017:1-4. doi: 10.1109/THS.2017.7943504

228. Yoon S, Ye W, Heidemann J, et al. SWATS: wireless sensor networks for steamflood and waterflood pipeline monitoring. IEEE Netw. 2011;25(1):50-56. doi: 10.1109/MNET.2011.5687953

229. Young KL. Hazmat Cam Wireless Video System. In: 1st Joint Emergency Preparedness and Response/Robotic and Remote Systems Topical Meeting. 2006:750-754.

230. Young KL. Second generation hazmat cam wireless tactical video system for hazardous response. 2009 IEEE Conf Technol Homel Secur HST. 2009:339-346. doi: 10.1109/THS.2009.5168056

231. Young SH, Martin P. RSTA sensor integration onto PackBot for urban operations. Proc SPIE. 2004;5422(September 2004):238-248. doi: 10. $1117 / 12.543034$

232. Young SH, Scanlon M V. Soldier/robot team acoustic detection. Unmanned Gr Veh Technol V. 2003;5083:419. doi: 10.1117/12.486323

233. Barker JLP, Macleod CJA. Development of a national-scale real-time Twitter data mining pipeline for social geodata on the potential impacts of flooding on communities. Environ Model Softw. 2019;115:213-227. doi: $10.1016 /$ j.envsoft.2018.11.013 
234. Yue Q, Liu F, Diao Y, et al. Research and application of a big data-driven intelligent reservoir management system. J Coast Res. 2018;82:270-279. doi: $10.2112 /$ si82-039.1

235. Zhang C, Bao S, She B, et al. Spatial intelligence for regional analysis. Int J Appl Geospatial Res. 2014;5(2):59-73. doi: 10.4018/ijagr.2014040105

236. Zhang M, Kang BH, Bai Q. Association rule based situation awareness in web-based environmental monitoring systems. Commun Comput Inf Sci. 2010;124 CCIS:224-232. doi: 10.1007/978-3-642-17644-9_25

237. Zhang SH, Yuan R, Zhang TX. Development and application of a threedimensional flood simulation platform. In: 11th International Symposium on Ecohydraulics. 2016:559-566.

238. Zhou L, Wu J, Zhang J, et al. The Integrated Surface Drought Index (ISDI) as an indicator for agricultural drought monitoring: theory, validation, and application in mid-eastern China. IEEE J Sel Top Appl Earth Obs Remote Sens. 2013;6(3):1254-1262. doi: 10.1109/JSTARS.2013. 2248077

239. Wei $\mathrm{H}$, Zeng $\mathrm{QA}, \mathrm{Hu} \mathrm{H}$, et al. Integrated urban evacuation planning framework for responding to human-caused disasters over a surface transportation network. Transp Res Rec. 2008;2041:29-37. doi: 10.3141/ 2041-04

240. Antunes P, Zurita G, Sapateiro C, et al. Development of a mobile situation awareness tool supporting disaster recovery of business operations. Ann Inf Syst. 2011;13:337-360. doi: 10.1007/978-1-4419-7406-8_17

241. Balta H, Bedkowski J, Govindaraj S, et al. Integrated data management for a fleet of search-and-rescue robots. J Field Robot. 2014;34(3):539-582. doi: 10.1002/rob.21651

242. Kohlbrecher S, Romay A, Stumpf A, et al. Human-robot teaming for rescue missions: team ViGIR's approach to the 2013 DARPA Robotics Challenge Trials. J Field Robot. 2015;32(3):352-377. doi: 10.1002/rob. 21558

243. US Office of Nuclear Security and Incident Response: Division of Preparedness and Response. Japan Incident Response After Action Report for the Fukushima Dai-Ichi Accident. 2011. https://www.nrc. gov/docs/ML1125/ML112580203.pdf. Accessed July 23, 2019.

244. Basu S, Roy S, Dasbit S. A post-disaster demand forecasting system using principal component regression analysis and case-based reasoning over smartphone-based DTN. IEEE Trans Eng Manag. 2019;66(2):224-239. doi: 10.1109/TEM.2018.2794146

245. Texas Health and Human Services. Texas Department of State Health Services Hurricane Harvey Response After-Action Report. 2018. https:// sk75w2kudjd3fv2xs2cvymrg-wpengine.netdna-ssl.com/wp-content/ uploads/2018/08/Texas-DSHS-Hurricane-Harvey-AAR-FINAL.pdf. Accessed July 23, 2019.

246. Texas Commission on Environmental Quality. Hurricane Harvey Response 2017 After-Action Review Report. https://www.tceq.texas. gov/assets/public/response/hurricanes/hurricane-harvey-after-actionreview-report.pdf. Published 2018. Accessed July 23, 2019.

247. Sonoma County EOC. October 2017 Complex Fires: Emergency Operations Center After Action Report \& Improvement Plan County of Sonoma. 2018. https://sonomacounty.ca.gov/WorkArea/Download Asset.aspx?id=2147560486. Accessed July 23, 2019.

248. Flagler County Board of County Commisioners. Hurricane Matthew After-Action Report. 2017. http://www.flaglercounty.org/document center/BOCC\%20administration/Matthew/Flagler\%20County\%20-\% 20Hurricane\%20Matthew\%20After\%20Action\%20Report\%20\%20Final \%20-\%20\%20June\%2020....pdf. Accessed July 23, 2019.

249. Baltimore City Fraternal Order of Police: Lodge $\# 3$. After action review: a review of the management of the 2015 Baltimore riots. http://www. fop3.org/wp-content/uploads/2015/07/AAR-Final.pdf. Published 2015. Accessed July 23, 2019.

250. Carafano JJ, Florance C, Kaniewski D. The Ebola Outbreak of 2013 2014: an assessment of U.S. actions. The Heritage Foundation. http:// report.heritage.org/sr166. Published 2015. Accessed July 23, 2019.

251. Information Technology Disaster Resource Center. Hurricane Sandy Response After Action Report \& Recommendations. https://www. fema.gov/media-library-data/20130726-1923-25045-7442/sandy_fema_ aar.pdf. Published 2013. Accessed July 23, 2019.

252. Hasegawa R. Disaster Evacuation from Japan's 2011 Tsunami Disaster and the Fukushima Nuclear Accident. Iddri. 2013;5(13). https://www. iddri.org/sites/default/files/import/publications/study0513_rh_devast-report. pdf. Accessed July 23, 2019.

253. DHS. DHS H1N1 After Action Report: Executive Summary. 2010. doi: $10.1558 /$ jsrnc.v4il.24. https://www.hsdl.org/?view\&did=783079. Accessed July 23, 2019.

254. Titan Systems Corporation. Arlington County: After-Action Report on the Response to the September 11 Terrorist Attack on the Pentagon. 2002. https://permanent.access.gpo.gov/lps21127/after_ report.pdf. Accessed July 23, 2019.

255. ABSG Consulting Inc. After Action Review of the November 28, 2016, Firestorm. http://wildfiretoday.com/documents/AAR_ChimneyTops2. pdf. Published 2017. Accessed July 23, 2019.

256. Becher K, Gustafsson S, Koudelka O, et al. Integrated space technology on small aircraft for instant situational awareness in disaster situations. In: Proceedings of the International Astronautical Congress, IAC. Vol 6. 2012:4878-4887.

257. Bhandari B, Marthafifsa AB, Hazarika MK, et al. Intricacies of implementing an ITU-T X.1303 cross-agency situational-awareness platform in Maldives, Myanmar, and the Philippines. Proc 2016 ITU Kaleidosc Acad Conf. 2017. doi: 10.1109/ITU-WT.2016.7805726

258. Nunavath V, Radianti J, Comes T, et al. The impacts of ICT support on information distribution, task assignment for gaining teams' situational awareness in search and rescue operations. Adv Intell Syst Comput. 2016;425:443-456. doi: 10.1007/978-3-319-28658-7_38

259. Bellini S, Ferrarini N, Santucci U. Implementation of an integrated information system for the management of swine vesicular disease surveillance activities in Italy. Vet Ital. 2007;43(3):533-539.

260. Berk V, Chung W, Crespi V, et al. Process query systems for surveillance and awareness. In: 7th World Multiconference on Systemics, Cybernetics and Informatics, Vol Xii, Proceedings. 2003:490-495.

261. Bhanumurthy V, Behera G. Deliverables from space data sets for future disaster management - present and future trends. Int Arch Photogramm Remote Sens Spat Inf Sci. 2008;XXXVII(B8):263-270. doi: 10.1.1.431. 4645

262. Bhanumurthy V, Rao KV, Rao SS, et al. Enabling heterogenous multiscale database for emergency service functions through geoinformation technologies. Int Arch Photogramm Remote Sens Spat Inf Sci - ISPRS Arch. 2014;XL-8(1):7-14. doi: 10.5194/isprsarchives-XL-8-7-2014

263. Boddhu S, Flagg R, Grzebala P, et al. A generic sensor fusion architecture for enhancing situational awareness. IEEE Natl Aerosp Electron Conf 2014. 2015:143-148. doi: 10.1109/NAECON.2014.7045792

264. Boersma K, Wagenaar P, Wolbers J. Negotiating the "trading zone". Creating a shared information infrastructure in the dutch public safety sector. J Homel Secur Emerg Manag. 2012;9(2). doi: 10.1515/15477355.1965

265. Bogdan G, Lewis G, Seroka AM, et al. 252. Poison center operates public information hotline for 2009/2010 novel H1N1 pandemic. NACCT Abstr Clin Toxicol. 2011;49(6):598. doi: 10.1080/15563650.2016. 1197486

266. Bossu R, Roussel F, Fallou L, et al. LastQuake: from rapid information to global seismic risk reduction. Int J Disaster Risk Reduct. 2018;28 (November 2017):32-42. doi: 10.1016/j.ijdrr.2018.02.024

267. Boxberger T, Fleming K, Pittore M, et al. The multi-parameter wireless sensing system (MPwise): its description and application to earthquake risk mitigation. Sensors (Basel). 2017;17(10). doi: 10.3390/s17102400

268. Abu-Elkheir M, Hassanein HS, Oteafy SMA. Enhancing emergency response systems through leveraging crowdsensing and heterogeneous data. 2016 Int Wirel Commun Mob Comput Conf IWCMC 2016. 2016:188-193. doi: 10.1109/IWCMC.2016.7577055

269. Bozkurt A, Lobaton E, Sichitiu M, et al. Biobotic insect swarm based sensor networks for search and rescue. Signal Process Sensor/Information 
Fusion, Target Recognit XXIII. 2014;9091(June 2014):90911L. doi: 10. $1117 / 12.2053906$

270. Bradley CA, Rolka H, Walker D, et al. BioSense: implementation of a National Early Event Detection and Situational Awareness System. MMWR Suppl. 2005;54:11-19. https://www.cdc.gov/mmwR/preview/ mmwrhtml/su5401a4.htm. Accessed July 23, 2019.

271. Bronstein A, Buscema M, Esfahani A, et al. 113. Locating the source of public health events using intelligent adaptive systems: 2011 United States listeriosis outbreak linked to whole cantaloupes. In: 2013 Annual Meeting of the NACCT: Clinical Toxicology. Vol 51. 2013:625-626.

272. Bronstein AC, Lodwick WA, Buscema MP. 19. Use of artificial adaptive system software for real-time Poison Center outbreak localization. In: XXXIV International Congress of the EAPCCT: Clinical Toxicology. Vol 52. 2014:303-304.

273. Brown JD, Salmanian M, Li M. Opportunistic situational awareness dissemination at the tactical edge. Proc - IEEE Mil Commun Conf MILCOM. 2014:1229-1237. doi: 10.1109/MILCOM.2014.205

274. Brunke S, Aubé G, Legaré S, et al. Analysis and remediation of the 2013 Lac-Mégantic train derailment. Int Arch Photogramm Remote Sens Spat Inf Sci - ISPRS Arch. 2016;41(July):17-23. doi: 10.5194/isprsarchives-XLIB8-17-2016

275. Burkard S, Fuchs-Kittowski F, Muller R, et al. Flood management platform for small catchments with crowd sourcing. 2018 5th Int Conf Inf Commun Technol Disaster Manag ICT-DM 2018. 2019. doi: 10.1109/ ICT-DM.2018.8636378

276. Burman J, Hespanha J, Madhow U, et al. Bio-inspired UAV routing, source localization, and acoustic signature classification for persistent surveillance. Ground/Air Multisens Interoperability, Integr Netw Persistent ISR II. 2011;8047(May 2011):80470Y. doi: 10.1117/12.882802

277. Burnett JD, Wing MG. A low-cost near-infrared digital camera for fire detection and monitoring. Int J Remote Sens. 2018;39(3):741-753. doi: 10.1080/01431161.2017.1385109

278. Cai T. Artificial neural network for industrial and environmental research via air quality monitoring network. In: Handbook of Research on Demand-Driven Web Services: Theory, Technologies, and Applications. 2014:399-419. doi: 10.4018/978-1-4666-5884-4.ch019

279. Akanbi AK, Masinde M. A framework for accurate drought forecasting system using semantics-based data integration middleware. AFRICOMM 2015, LNICST. 2016;171:106-110. doi: 10.1007/978-3-319-43696-8

280. Campbell TC, Hodanics CJ, Babin SM, et al. Developing open source, self-contained disease surveillance software applications for use in resource-limited settings. BMC Med Inform Decis Mak. 2012;12:99. doi: $10.1186 / 1472-6947-12-99$

281. Campbell TC, Hodanics CJ, Mistry ZS, et al. Open ESSENCE: an opensource, self-contained disease surveillance software application for global use. Johns Hopkins APL Tech Digest. 2014;32(4):659-666.

282. Canisius F, Honda K, Tokunaga M. Updating geomorphic features of watersheds and their boundaries in hazardous areas using satellite synthetic aperture radar. Int J Remote Sens. 2009;30(22):5919-5933. doi: $10.1080 / 01431160902791879$

283. Castanhari RES, Dos Santos Rocha R, De Andrade SC, et al. A software architecture to integrate sensor data and volunteered: geographic information for flood risk management. In: Geospatial Data and Geographical Information Science Proceedings of the ISCRAM 2016 Conference: Rio de Janeiro, Brazil. May 2016.

284. Chandra-Sekaran AK, Nwokafor A, Johansson P, et al. ZigBee sensor network for patient localization and air temperature monitoring during emergency response to crisis. Proc - 2nd Int Conf Sens Technol Appl, SENSORCOMM 2008, Incl MESH 2008 Conf Mesh Networks; ENOPT 2008 Energy Optim Wirel Sensors Networks, UNWAT 2008 Under Water Sensors Syst. 2008:233-238. doi: 10.1109/SENSORCOMM. 2008.67

285. Chandra-Sekaran A-K, Flaig G, Kunze C, et al. Efficient resource estimation during mass casualty emergency response based on a location aware disaster aid network. In: EWSN 2008, LNCS. Vol 4913. 2008:205-220.
286. Che Ku Abdullah CKAF, Baharuddin NZS, Ariff MFM, et al. Integration of point clouds dataset from different sensors. Int Arch Photogramm Remote Sens Spat Inf Sci - ISPRS Arch. 2017;42(2W3):9-15. doi: 10.5194/isprsarchives-XLII-2-W3-9-2017

287. Chen AY, Peña-Mora F, Mehta SJ, et al. A GIS approach to equipment allocation for structural stabilization and civilian rescue. In: ISCRAM 2010 - 7th International Conference on Information Systems for Crisis Response and Management: Defining Crisis Management 3.0, Proceedings. 2010.

288. Chen AY, Peña-Mora F, Plans AP, et al. Supporting urban search and rescue with digital assessments of structures and requests of response resources. Adv Eng Informatics. 2012;26(4):833-845. doi: 10.1016/j.aei. 2012.06.004

289. Cheng E, Meiss K, Park K, et al. Contextual geotracking service of incident markers in disaster search-and-rescue operations. Proc - 2016 IEEE 15th Int Symp Netw Comput Appl NCA 2016. 2016:22-26. doi: 10.1109/ NCA.2016.7778586

290. Akkaş MA, Sokullu R, Balci A. Wireless sensor networks in oil pipeline systems using electromagnetic waves. ELECO 2015 - 9th Int Conf Electr Electron Eng. 2016:143-147. doi: 10.1109/ELECO.2015.7394548

291. Cheng MY, Chiu KC, Hsieh YM, et al. Development of BIM-based realtime evacuation and rescue system for complex buildings. ISARC 2016 33rd Int Symp Autom Robot Constr. 2016;(Isarc):999-1008. doi: 10.22260/ isarc2016/0120

292. Chipman R, Wuerfel R. Network based information sharing between emergency operations center. 2008 IEEE Int Conf Technol Homel Secur HST'08. 2008:155-160. doi: 10.1109/THS.2008.4534441

293. Chronaki CE, Kontoyiannis V, Argyropaidas P, et al. Innovation in disaster management: report from Exercise EU POSEIDON 2011. In: ERCIM NEWS. Vol 88. 2011. https://ercim-news.ercim.eu/en88/ri/ innovation-in-disaster-management-report-from-exercise-eu-poseidon2011. Accessed July 23, 2019

294. Chu A, Savage R, Willison D, et al. The use of syndromic surveillance for decision-making during the H1N1 pandemic: a qualitative study. BMC Public Health. 2012;12(1):1. doi: 10.1186/1471-2458-12-929

295. Chughtai S. Typhoon Haiyan: the response so far and vital lessons for the Philippines recovery. Oxfam. https://www.oxfamamerica.org/ static/media/files/bn-typhoon-haiyan-philippines-response-071213-en. pdf. Published 2013. Accessed July 23, 2019.

296. Chun SA, Atluri V, Vaidya JS, et al. Citizen-to-citizen resource sharing in emergency response. New Approaches, Methods, Tools Urban E-planning. 2018:130-164. doi: 10.4018/978-1-5225-5999-3.ch005

297. Clark AJ, Holliday P, Chau R, et al. Collaborative geospatial data as applied to disaster relief: Haiti 2010. Commun Comput Inf Sci. 2010;122 CCIS:250-258. doi: 10.1007/978-3-642-17610-4_29

298. Cooper KR. Long-term evaluation of a fiber optic-based irreversible moisture sensor. Smart Struct Mater 2004 Smart Sens Technol Meas Syst. 2004;5384(July 2004):64. doi: 10.1117/12.539154

299. Coppini G, Marra P, Lecci R, et al. SeaConditions: a web and mobile service for safer professional and recreational activities in the Mediterranean Sea. Nat Hazards Earth Syst Sci. 2017;17(4):533-547. doi: 10.5194/nhess-17-533-2017

300. Cummings ML, Guerlain S. Developing operator capacity estimates for supervisory control of autonomous vehicles. Hum Factors. 2007;49(1):115. doi: $10.1518 / 001872007779598109$

301. Alamdar F, Kalantari M, Rajabifard A. Towards multi-agency sensor information integration for disaster management. Comput Environ Urban Syst. 2016;56:68-85. doi: 10.1016/j.compenvurbsys.2015.11.005

302. Curran M, Howley E, Duggan J. An analytics framework to support surge capacity planning for emerging epidemics. DH 2016 - Proc 2016 Digit Heal Conf. 2016:151-155. doi: 10.1145/2896338.2896354

303. Dao T, Khalil K, Roy-Chowdhury AK, et al. Energy efficient object detection in camera sensor networks. Proc - Int Conf Distrib Comput Syst. 2017:1208-1218. doi: 10.1109/ICDCS.2017.152

304. Davies AG, Gunapala S, Soibel A, et al. A novel technology for measuring the eruption temperature of silicate lavas with remote sensing: 
application to Io and other planets. J Volcanol Geotherm Res. 2017;343:1 16. doi: 10.1016/j.jvolgeores.2017.04.016

305. Dbouk M, Mcheick H, Sbeity I. CityPro; an integrated city-protection collaborative platform. Procedia Comput Sci. 2014;37:72-79. doi: 10. 1016/j.procs.2014.08.014

306. De Cillis F, Inderst F, Pascucci F, et al. Improving the safety and the operational efficiency of emergency operators via on field situational awareness. Chem Eng Trans. 2016;53(2009):331-336. doi: 10.3303/ CET1653056

307. De Visser EJ, Freedy E, Payne JJ, et al. AREA: a mobile application for rapid epidemiology assessment. Procedia Eng. 2015;107:357-365. doi: 10. 1016/j.proeng.2015.06.092

308. DeFraites RF, Chambers WC. Gaining experience with military medical situational awareness and geographic information systems in a simulated influenza epidemic. Mil Med. 2007;172(10):1071-1076. doi: 10.7205/ milmed.172.10.1071

309. Dejpichai R. A tsunami after-action report: active disease surveillance in tsunami affected areas, Southern Thailand, December 2004-February 2005. http://d-scholarship.pitt.edu/21990/. Published June 20, 2014. Accessed July 23, 2019.

310. Demir F, Ahmad S, Calyam P, et al. A next-generation augmented reality platform for mass casualty incidents (MCI). J Usability Stud. 2017;12(4):193-214.

311. Demir I, Krajewski WF. Towards an integrated flood information system: centralized data access, analysis, and visualization. Environ Model Softw. 2013;50:77-84. doi: 10.1016/j.envsoft.2013.08.009

312. Alferes J, Tik S, Copp J, et al. Advanced monitoring of water systems using in situ measurement stations: data validation and fault detection. Water Sci Technol. 2013;68(5):1022-1030. doi: 10.2166/wst.2013.302

313. Deng Y, Tang Z, Chen Y, et al. Information Integration based on open geospatial database connectivity specification. In: ISPRS Technical Commission IV, ASPRS/CaGIS 2010 Fall Specialty Conference. 2010.

314. Deveci HS, Koru A, Sakarya U, et al. The benefits and challenges of having an open and free basis satellite data sharing platform in Turkey: Gezgin. Int Arch Photogramm Remote Sens Spat Inf Sci - ISPRS Arch. 2016;41(July):1341-1347. doi: 10.5194/isprsarchives-XLI-B8-1341-2016

315. Di Ciaccio R, Pullen J, Breimyer P. Enabling distributed command and control with standards-based geospatial collaboration. 2011 IEEE Int Conf Technol Homel Secur HST 2011. 2011:512-517. doi: 10.1109/ THS.2011.6107921

316. Di Lazzaro M, Angino G, Piemontese M, et al. COSMO-SkyMed: the dual-use component of a geospatial system for environment and security. IEEE Aerosp Conf Proc. 2008:1-10. doi: 10.1109/AERO.2008.4526278

317. Di Lecce V, Amato A, Calabrese M. Data integration in distributed medical information systems. Can Conf Electr Comput Eng. 2008;180:14971501. doi: 10.1109/CCECE.2008.4564791

318. Dimitrov V, Jagtap V, Skorinko J, et al. Human-centered design of a cyber-physical system for advanced response to Ebola (CARE). Proc Annu Int Conf IEEE Eng Med Biol Soc EMBS. 2015;2015Novem:6856-6859. doi: 10.1109/EMBC.2015.7319968

319. Ding XL, Huang DF, Yin JH, et al. A new generation of multi-antenna GPS system for landslide and structural deformation monitoring. Adv
Build Technol. 2002;2:1611-1618. doi: 10.1016/b978-008044100-9/ 50199-6

320. Ding Y, Zhu Q, Lin H. An integrated virtual geographic environmental simulation framework: a case study of flood disaster simulation. GeoSpatial Inf Sci. 2014;17(4):190-200. doi: 10.1080/10095020.2014.988199

321. Dipierro S, Nemeroff J, Orpilla M, et al. Soldier-Level Communications Environment (SLICE)/soldier radio waveform (SEW). Ferroelectrics. 2006;342(1):141-149. doi: 10.1080/00150190600946294

322. Dogan H, Svagard I, Holter T. Trial of a Special End User Terminal that Aids Field Operators during Emergency Rescue Operations. In: 3rd International Conference on Information Systems for Crisis Response and Management $\mathcal{E}$ 4th International Symposium on Geo-Information for Disaster Management. 2008:273-284.

323. Amore M, Bonaccorso A, Ferrari F, et al. Eolo: software for the automatic on-line treatment and analysis of GPS data for environmental monitoring. Comput Geosci. 2002;28(2):271-280. doi: 10.1016/S0098-3004(01) 00072-3

324. Donahoo M, Steckler B. Emergency mobile Wireless Networks Flyaway Communications (FLAC) with WIMAX 802.16 technology. Proc - IEEE Mil Commun Conf MILCOM. 2005;2005. doi: 10.1109/MILCOM.2005. 1606030

325. Enanoria WT, Crawley AW, Tseng W, et al. The epidemiology and surveillance response to pandemic influenza $A(H 1 N 1)$ among local health departments in the San Francisco Bay Area. BMC Public Health. 2013;13(1). doi: 10.1186/1471-2458-13-276

326. Erickson P, Weinert A, Breimyer P, et al. Designing public safety mobile applications for disconnected, interrupted, and low bandwidth communication environments. 2013 IEEE Int Conf Technol Homel Secur HST 2013. 2013:790-796. doi: 10.1109/THS.2013.6699028

327. Erol B. Evaluation of high-precision sensors in structural monitoring. Sensors. 2010;10(12):10803-10827. doi: 10.3390/s101210803

328. Espiritu M, Patil U, Cruz H, et al. Evacuation of a neonatal intensive care unit in a disaster: lessons from hurricane Sandy. Pediatrics. 2014;134(6): e1662-e1669. doi: 10.1542/peds.2014-0936

329. Esposito M, Marchi AZ. HyperCube the intelligent hyperspectral imager. 2nd IEEE Int Work Metrol Aerospace, Metroaerosp 2015 - Proc. 2015:547. 550. doi: 10.1109/MetroAeroSpace.2015.7180716

330. Fajardo JTB, Yasumoto K, Ito M. Content-based data prioritization for fast disaster images collection in delay tolerant network. 2014 7th Int Conf Mob Comput Ubiquitous Networking, ICMU 2014. 2014:147-152. doi: 10.1109/ICMU.2014.6799086

331. Fall K, Iannaccone G, Kannan J, et al. A disruption-tolerant architecture for secure and efficient disaster response communications. In: ISCRAM 2010 7th International Conference on Information Systems for Crisis Response and Management: Defining Crisis Management 3.0, Proceedings. 2010.

332. Fan S, Blair C, Brown A, et al. A multi-function public health surveillance system and the lessons learned in its development: the Alberta Real Time Syndromic Surveillance Net. Can J Public Heal. 2010;101(6):454458. doi: $10.1007 / \mathrm{bf03403963}$

333. Fang S, Xu L, Pei H, et al. An integrated approach to snowmelt flood forecasting in water resource management. IEEE Trans Ind Informatics. 2014;10(1):548-558. doi: 10.1109/TII.2013.2257807 